\title{
Effect of Zeolite on Small Intestine Microbiota of Broiler Chickens: A Case Study
}

\author{
Sandrine Le Gall-David ${ }^{1 *}$, Vincent Meuric ${ }^{1,2}$, Gaëlle Benzoni' ${ }^{3}$, Sophie Valière ${ }^{4,5}$, Alain Guyonvarch ${ }^{3}$, \\ Jacques Minet1,2, Martine Bonnaure-Mallet1,2, Frédérique Barloy-Hubler ${ }^{6,7}$
}

\author{
${ }^{1}$ Microbiology Team EA 1254, Université de Rennes 1, Rennes, France \\ ${ }^{2}$ Hospital, Rennes, France \\ ${ }^{3}$ Invivo NSA, Saint Nolff, France \\ ${ }^{4}$ INRA, UAR 1209, Castanet-Tolosan, France \\ ${ }^{5}$ INRA, GeT-PlaGe, Genotoul, Castanet-Tolosan, France \\ ${ }^{6}$ CNRS-IGDR-UMR 6290, Rennes, France \\ ${ }^{7}$ AMADEUS Platform-Biosit, Rennes, France \\ Email: ^Sandrine.legall-david@univ-rennes1.fr
}

How to cite this paper: Gall-David, S.L., Meuric, V., Benzoni, G., Valière, S., Guyonvarch, A., Minet, J., Bonnaure-Mallet, M. and Barloy-Hubler, F. (2017) Effect of Zeolite on Small Intestine Microbiota of Broiler Chickens: A Case Study. Food and Nutrition Sciences, 8, 163-188.

http://dx.doi.org/10.4236/fns.2017.81011

Received: November 19, 2016

Accepted: January 20, 2017

Published: January 23, 2017

Copyright $\odot 2017$ by authors and Scientific Research Publishing Inc This work is licensed under the Creative Commons Attribution International License (CC BY 4.0).

http://creativecommons.org/licenses/by/4.0/

\begin{abstract}
After ban of antibiotics growth promoters (AGP) in Europe in 2006, use of non-medicated gut microbiota regulators as feed additives has dramatically increased. This study aimed at describing the effects of a copper-exchanged zeolite on broiler growth performance, small intestine morphology and microbiota composition. Illumina Sequencing of the V3-V4 region of the 16S rRNA gene was employed to study the small intestine microbiota. This microbiota with copper-exchanged zeolite treated-chickens was significantly less diverse with an almost exclusive presence of Lactobacillus johnsonii and Lactobacillus reuteri. These Lactobacilli are correlated with increased diameter, length and weight of the three segments of the small intestine and decreased viscosity of the intestinal content, suggesting probiotic action. The tested copper-exchanged zeolite would act as a prebiotic, selecting a "favorable" flora for the healthy broilers development.
\end{abstract}

\section{Keywords}

Microbiota, Chicken, Growth Promoting, Zeolite, Bacitracin

\section{Introduction}

Domestic chickens have a special place in society. Commercial poultry production is one of the most important sources of animal protein for human consumption, not suffering from any cultural or religious interdiction and is an important economic activity in many countries, with over 60 billion birds used in the production of meat and eggs each year. Despite their strong impact on technical and economical farm 
performance, little is known about microorganisms housed in the chicken gastrointestinal tract (GIT). Yet, the complex microbial community (microbiota) of the gastrointestinal tract plays an important role in the health of animal and can be considered as an important metabolic "organ". Composition of the intestinal microbiota is dynamic with spatial shifts along each GIT region in relation to environmental changes [1]. The entire GIT of chicken is estimated to house 640 species of bacteria from 140 different genera [2].

Sub-therapeutic concentrations of antibiotics, known as antibiotics growth promoters (AGPs) have long been used in the food-producing industry. Their addition enhances feed efficiency, reduce mortality and improve the overall health of livestock [3]. Their mode of action is thought to be due to a direct or indirect overall reduction or modification in bacterial numbers, as it is strongly suggested by their lack of effect on axenic broilers [4]. The proposed mechanisms involve a reduction of microbial nutrient utilization, an enhancement of nutrient absorption due to a thinner mucus layer and healthy functional enterocytes, a decreased production of unwanted bacterial metabolites such as toxins and a reduction of intestinal infections [5]. Direct action on the host's intestinal immune functions have also been suggested [6]. Finally, their addition in animal's feed results in a decrease of nutrient amounts needed to produce a market-size chicken and enhances birds' growth without negative effects on meat quality if withdrawal delays are observed [7]. The first evidence of AGPs performance effect dates back to 1940 [8] and has since been echoed by many studies [9] [10]. The development of intensive livestock farming based on confinement of high number of birds, therefore increase risk of bacterial disease development and unbalanced gut microbiota. Subsequently, AGPs have been used in routine for decades to prevent disease and improve zootechnical performances [11]. However, their overuse has contributed to the emergence of drug resistant bacteria and to the accumulation of antibiotic residues in animal products and environment [12] [13] [14] [15]. Thereby, AGPs were banned from farming practices in 2006 in Europe, letting farmers to increased mortality, degraded techno-economical results and decreased animal welfare. This raised the need for safe and efficient alternatives that could increase nutrient availability for the animal, improve host immunity and intestinal microbiota [16].

Thus, many feed additives have emerged in poultry nutrition such as probiotics [17], prebiotics [18] [19], microelements [20] [21], digestive enzymes [22] [22] plants extracts or essential oils [24] [25] [26] and clays [27] [28] [29]. Particularly, among clays, action of ion-exchanged clays on microbiota is well described. Song et al., Tang et al. and Xia et al., pointed them out as good candidates for alternative to AGPs [30] [31] [32]. Nevertheless, regarding the microbiota, most of the studies with ion-exchanged clays focus on counts of pathogenic bacteria (mainly Escherichia coli, Clostridium and Salmonella) and do not investigate the impact of the additive on the overall microbiota balance.

Clays such as particular bentonite, kaolinite, sepiolite, montmorillonite and copperexchanged zeolite have antibacterial properties [30].

As a consequence, in this study, we investigated the influence of a patented copperexchanged zeolite (B-SAFE, Pancosma) on broilers microbiota composition compared 
to negative control and AGP treatment.

\section{Materials and Methods}

\subsection{Animals and Experimental Design}

Animal experiments were performed in accordance with the Invivo NSA ethical committee in animal experimentation (CNREEA Registration Code C2EA-52, Protocol no. 2012-12-20 4R). This study was designed to obtain intestinal microbiota samples from control chickens and from chickens receiving either copper-exchanged zeolite or zinc bacitracin that had significantly higher growth compared to negative control. A total of 105 unvaccinated 1-day-old male chicks (strain Ross PM3) were obtained from a local commercial hatchery and grown over a 21-day experimental period. Thirty-five chicks for each groups were randomly and equally assigned to one of the 3 dietary treatment groups: 1) "control group" exclusively fed with a corn-soybean-wheat diet "zeolite group" that received the same diet as the control group, supplemented with $6 \mathrm{mg}$ of a patented copper-exchanged zeolite/kg of feed (B-SAFE, Patent no. FR 05 03671, Pancosma) and 3) a "bacitracin group" that received the same diet as the control group but was continuously supplemented over the whole trial period with sub-therapeutic doses of soluble zinc bacitracin (Bacivet $\mathrm{S}^{\circ}$, Zoetis) at $30 \mathrm{mg} / \mathrm{L}$ in drinking water, equivalent to $48 \mathrm{ppm}$ of zinc bacitracin in feed. Each chicken group was housed in a $1-\mathrm{m}^{2}$ woodchips litterpen in a controlled broiler house. Environmental conditions were adapted to animal's needs: temperature progressively dropped from $33^{\circ} \mathrm{C}$ to reach $27^{\circ} \mathrm{C}$ at 21 days, light progressively dropped from $24 \mathrm{~h}$ of light the first 4 days, to reach 6 hours of night per day in 21 days. Confinement at high stocking density $\left(45.5 \mathrm{birds} / \mathrm{m}^{2}\right)$ was chosen to fit the intensive poultry farming conditions. Experimental sections were separated by two empty ones to prevent contact between animals and litter exchanges. For all groups, feed and water were provided ad libitum. On day 21, all birds were picked from each treatment, avoiding birds with extreme weight. These animals were individually weighed and slaughtered by electrical stunning and bleeding. Small batches of chickens from the same experimental groups were designed for slaughtering, in order to limit the delay between death and intestinal sampling to avoid intestinal microbiota post-mortem disturbance. Each animal was manually eviscerated and the small intestine (from the output of the gizzard to the beginning of caeca) was carefully collected, transferred into a sterile stomacher bag, weighed and rapidly frozen at $-20^{\circ} \mathrm{C}$ then stored at $-80^{\circ} \mathrm{C}$.

\subsection{Gut Morphology}

Small intestine samples $(\mathrm{N}=35$ by sample) were brought back to room temperature. Gut diameters, length and weight were measured separately for each of the three small intestinal sections, distinguished using anatomical criteria; duodenum was considered from the first few centimetres to the output of the duodenal loop, the jejunum was sampled from the end of the duodenum to the Meckel's diverticulum and the ileum was sampled from the Meckel's diverticulum to the ileo-caecal junction. All measures were done, on the same day and by the same persons to ensure uniformity. Viscosity of intestinal content was observed during DNA extraction preparation and evaluated 
using an adaptation of a simple published procedure [33], measuring the time required for a constant volume of liquid to drain a plastic pipet, at room temperature.

\subsection{DNA Extraction}

Whole small intestines were suspended in $10 \mathrm{ml}$ lysis buffer ASL (Qiagen, France), placed in filter stomacher bag and submitted to two one-minute consecutive cycles in an AES Smascher (BioMérieux, France). Two lysis were performed by treatment, samples were labelled A for control, B for zeolite and C for bacitracin and numbered with 1 and 2. These two extractions were pooled to give A, B and C samples numbered 3. Each group was separated and mixed in two separated batches (Figure S1). DNA was then extracted from each samples (from A1 to $\mathrm{C} 3$ ) using a bead-beating procedure. Briefly, $0.5 \mathrm{~g}$ of beads of diameter $425 \mu \mathrm{m}$ and $0.5 \mathrm{~g}$ of beads of diameter $600 \mu \mathrm{m}$ (Sigma Aldrich, France) were added to $1.5 \mathrm{ml}$ of the lysate and homogenized on a bead-beater (Scientific industry, UK) for $10 \mathrm{~min}$ at full speed. The samples were then heated at $70^{\circ} \mathrm{C}$ for $15 \mathrm{~min}$, followed by centrifugation (9300 g, $5 \mathrm{~min}$ ), to separate DNA from glass beads and cellular debris. Then DNA was extracted using QIAamp DNA blood mini kit (Qiagen, France) following manufacturer recommendations.

\subsection{Sr RNA Amplification and Sequencing}

The V3-V4 region was amplified from each batch of each treatment group three DNA samples with the primers F343 and R784 using 30 amplification cycles with an annealing temperature of 65 degrees (an amplicon of $510 \mathrm{bp}$, although length varies depending on the organisms). Because MiSeq enables paired 250-bp reads, the ends of each read are overlapped and can be stitched together to generate extremely high-qua- lity, full-length reads of the entire V3 and V4 region in a single run. Single multiplexing was performed using homemade 6 bp index, which were added to R784 during a second PCR with 12 cycles using forward primer

(5'-AATGATACGGCGACCACCGAGATCTACACTCTTTCCCTACACGAC-3') and reverse primer

(5'-CAAGCAGAAGACGGCATACGAGAT-index-GTGACTGGAGTTCAGACGTGT-

3'). The resulting PCR products were purified and loaded onto the Illumina MiSeq cartridge according to the manufacturer instructions. The quality of the run was checked internally using PhiX, and then each pair-end sequences were assigned to its sample with the help of the previously integrated index. Each pair-end sequences were assembled using Flash sofware using at least a 10 bp-overlap between the forward and reverse sequences, allowing $10 \%$ of mismatch. Reads that could not be assembled were discarded. Secondly, all sequences were rechecked to eliminate those corresponding to internal control PhiX, those that still contained $\mathrm{N}$ bases and those that correspond to the host "Gallus gallus".

\subsection{Ecology Diversity and Taxonomic Identification}

Chicken small intestinal microbiota were analysed using both VAMPS (Visualization and Analysis of Microbial Population Structures [34]) and MG-RAST (Metagenome Rapid Annotation using Subsystem Technology, [35]) online servers. The species 
observed and estimated richness were evaluated using rarefaction curves and nonparametric ACE and Chaol tests [36] [37]. Alpha-diversities were estimated using Simpson-[38] and Shannon-indices [39]. Differences between microbiota were assessed using principal coordinate analysis $(\mathrm{PCoA})$ on Bray-Curtis distances and unweighted Unifrac [40]. Three-dimensional PCoA plots were generated using EMPeror software [41]. For taxonomic assignment and differential comparison of microbial class, order, family and genus, we compare SILVA [42], RDP-II [43] and Greengenes [44] databases. Reference sequences were only Bacteria (classified and unclassified sequences). For VAMPS, we used defaults parameter whereas for MG-RAST, we set the thresholds to $95 \%$ of identity and E-value of $1^{\mathrm{e}-100}$. For species determination and comparison, we used a homemade manually biocurated database, composed of V3V4 regions for all non-redundant bacterial genus identified in our samples. All these extracted sequences were aligned to determine if they can discriminate the bacterial species at a threshold value of $97 \%$. All assignations were based on $97 \%$ or greater identity. Sequences under this threshold were not assigned and grouped under "unclassified" taxon. 16S copy number correction was performed on genus representing more than $1 \%$ using $\operatorname{rnDB}$ (https://rrndb.umms.med.umich.edu).

\subsection{Statistical Analysis}

Numeric data collected were represented as mean \pm standard deviation. D'AgostinoPearson and Shapiro tests were performed to check the normality of data distribution. Data presenting normal distribution were compared using an unpaired Student's t-Test while data with a free distribution were compared by a non-parametric Mann-Whitney test. For both statistic tests, differences were considered statistically significant at $p<$ 0.05. Tests were carried out using GraphPad Prism v6 (GraphPad Software, San Diego, CA).

\section{Results}

\subsection{Zootechnical Conformity of the Study}

The objective of the study was to compare intestinal microbiota of chickens receiving efficient growth promoting additives to microbiota of negative control birds. Birds from copper-exchanged zeolite group were significantly heavier than birds of control group (809 $\mathrm{g}$ vs $762 \mathrm{~g}, p<0.05$ ). Birds from zinc bacitracin group were also significantly heavier than control group (852 $\mathrm{g}$ vs $762 \mathrm{~g}, p<0.05$ ). As a consequence, both supplemented groups were significantly heavier than the control. Those randomly sampled animals were then qualified for microbiota investigations (Figure 1).

\subsection{Comparative Gut Morphometry}

Copper-exchanged zeolite and zinc bacitracin supplemented chickens had significantly increased small intestines length and weight when compared with the control group (Figure 2(a)). Interestingly, diameters of jejunum from birds that received the control diet were significantly smaller when compared with birds in those supplemented diets. We observed the same trend for ileum and duodenum segments although the differences were not statistically significant (Figure 2(b)). Noticeably, the addition of copper- 


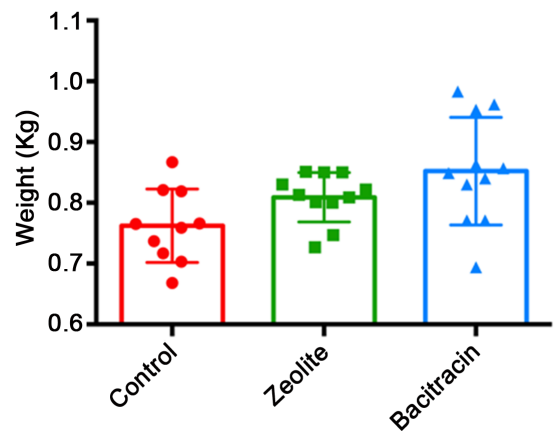

\begin{tabular}{|cc|}
\hline Zeolite vs. Control & \\
\hline P value & 0.0485 \\
\hline Significantly different $(P<0.005)$ & YES \\
\hline Mean \pm SEM of control & $0.762 \pm 0.019$ \\
\hline Mean \pm SEM of Zeolite & $0.809 \pm 0.012$ \\
\hline Different between means & $0.047 \pm 0.022$ \\
\hline Bacitracin vs. Control & \\
\hline$P$ value & 0.0145 \\
\hline Significantly different $(P<0.005)$ & YES \\
\hline Mean \pm SEM of control & $0.762 \pm 0.019$ \\
\hline Mean \pm SEM of Bacitracin & $0.852 \pm 0.026$ \\
\hline Different between means & $0.899 \pm 0.033$ \\
\hline
\end{tabular}

Figure 1. Graphs showing chicken body weight (BW) distribution as well as t-test results. Control in red circles, zeolte in green squares and bacitracin in blue triangles.

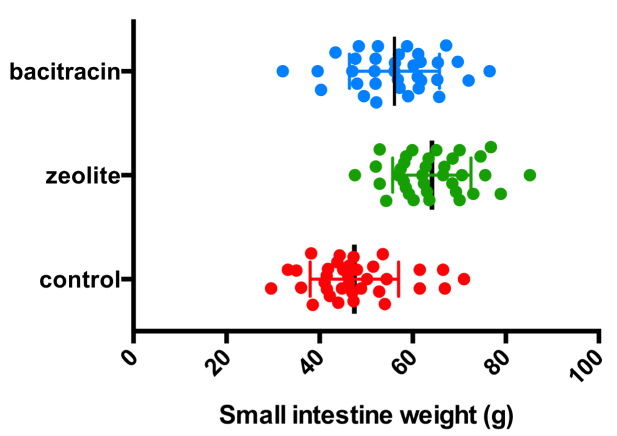

zeolite vs. control

bacitracin vs. control

Zeolite vs. control

$$
\begin{aligned}
& \mathrm{P} \text { value }<0.0001 * \\
& \mathrm{P} \text { value }=0.0004 * \\
& \mathrm{P} \text { value }=0.0005 *
\end{aligned}
$$

(a)
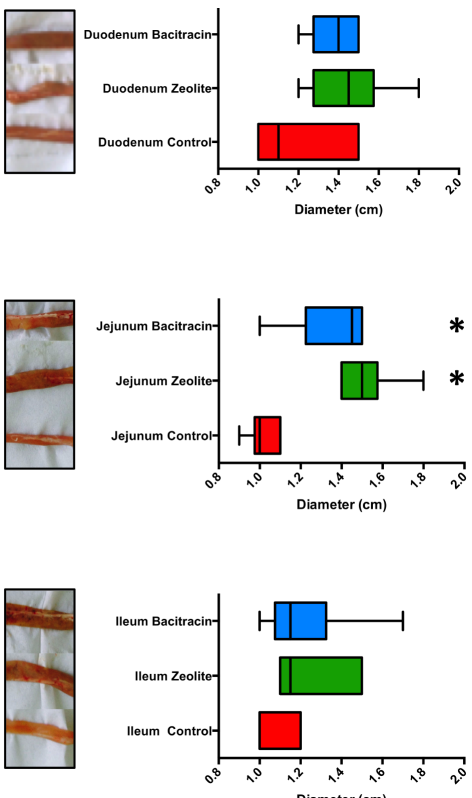

(b)

Figure 2. Effect of dietary treatment on small intestine morphology for chicken. (a) Small intestine weight (blue: Zn-bacitracin, green: B-SAFE copper-exchanged zeolite, red: control diet) for birds; (b) Three small intestine segments (duodenum, jejunum and ileum) diameters (in $\mathrm{cm}$ ), ${ }^{\star} P<$ 0.05. (Circles: control in red, Zeolite in green squares and Bacitracin in blue triangles).

exchanged zeolite to the diet resulted in a significantly higher weight and length of the jejunum and ileum when compared to both control and antibiotic treatments (Figure 3). The supernatant-fraction of stomached control small intestines were more viscous than those from supplemented groups, so much that pipetting was difficult for these samples, in accordance with previous description [33].

\subsection{Small Intestine Microbiota Comparisons}

\subsubsection{S Sequencing}

All reads all downloadable in the MG-RAST server under these accession numbers 4631783.3 (A1), 4631787.3 (A2), 4631785.3 (A3) 4631791.3 (B1) 4631789.3 (B2) (4631790.3) 

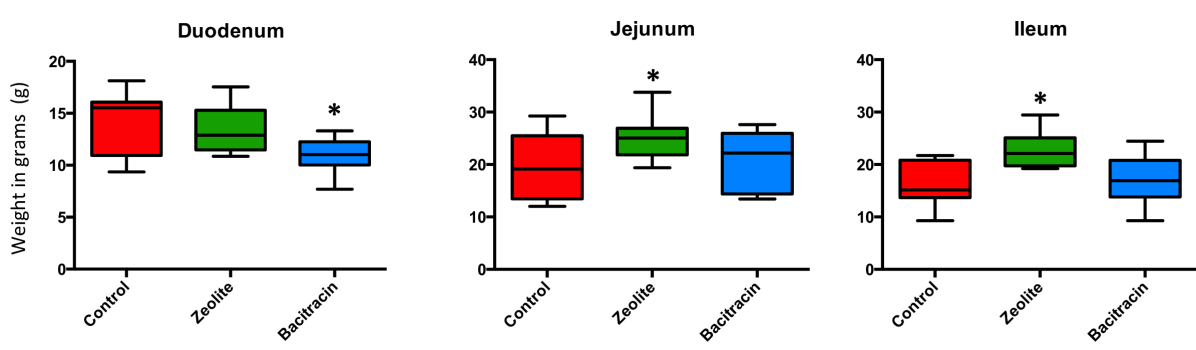

(a)
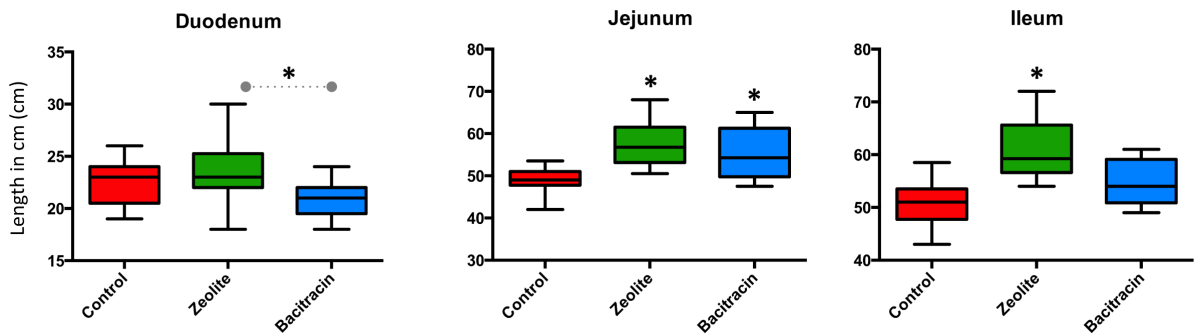

(b)

Figure 3. Weight (a) and length (b) of the three segments of the small intestine presented in by graphs. The three segments (duodenum, jejunum and ileum) and three treatments (blue: Zn-bacitracin, green: B-SAFE copper-exchanged zeolite, red: control diet) were compared. ${ }^{\star} P$ $<0.05$.

B3: 4631784.3 (C1): 4631786.3 (C2) 4631788.3 (C3) and in NCBI server under these accession number: Bioproject: PRJNA355230, BioSample: SRA: SRR5059408, SRR5059409, SRR5059410.

\subsubsection{Microbiota Ecology}

The PCoA plot showed a good clustering of triplicate samples (control triplicates: A1, A2, A3, zeolite triplicates: B1, B2, B3 bacitracin triplicates: C1, C2 C3) collected from each dietary treatment with a less defined clustering of bacitracin samples (Figure 4). This observation leads to the conclusion that both bacitracin and copper-exchanged zeolite influence the small intestine bacterial population and that the three bacterial populations are different. Interestingly and unexpectedly, the two supplemented diets (bacitracin and copper-exchanged zeolite), which lead to higher weights in the 36 individuals, have widely separated microbial populations.

To verify adequate sequencing depth of the three ureing datasets, rarefaction curves were performed, at both bacterial phylum and genus levels. These curves indicate a suitable depth of coverage. Indeed, although they do not reach the saturation phase, their slopes tend to plateau demonstrating, that a large part of the bacterial diversity was reached (Figure S2). A comparable number of phyla (12 to 13) was observed for all samples and the rarefaction curves tend to show that the bacitracin-treated community is less rich than control and copper-exchanged zeolite samples, reaching 138 versus 156 genus. This low richness is further confirmed by both observed (S) and estimated (Chao, ACE) richness curves (Figure S3) but these differences were not statistically significant. However, both Shannon and Simpson diversity indices show a small intestine microbiota of chicken treated with copper-exchanged zeolite less diverse in comparison with control and antibiotic diets. 


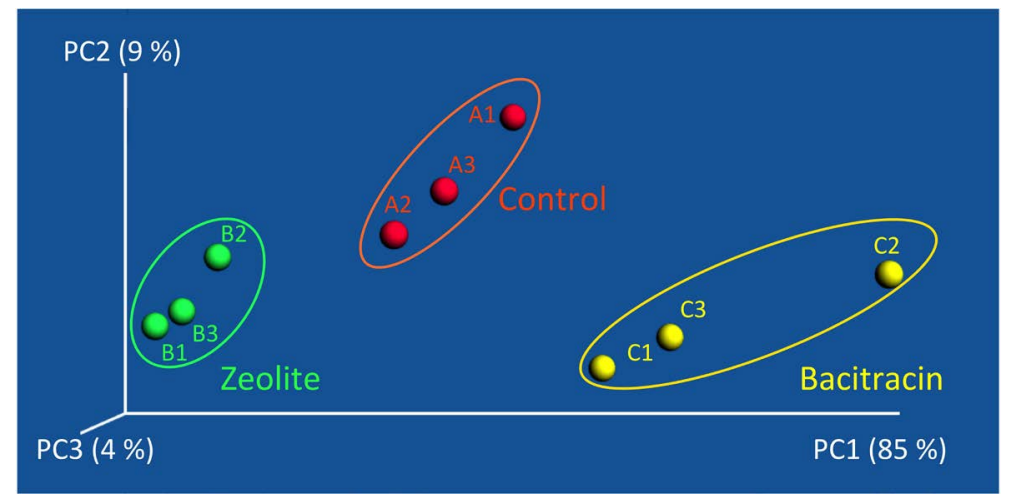

Figure 4. PCoA plot illustrating the beta-diversity of bacterial populations as a function of diet (control triplicates: A1, A2, A3 in red, zeolite triplicates: B1, B2, B3 in green and bacitracin triplicates: C1, C2, C3 in yellow).

\subsubsection{Phylum Comparison}

The predominant phylum in each group was Firmicutes, accounting for almost $90 \%$ of all sequences (Figure 5 and Figure S4). However, this number was found significantly different between animals treated with the feed additives with a high increase for copper-exchanged zeolite, reaching 99\%. For control and antibiotic treatments, Proteobacteria and Actinobacteria phyla were also detected. Bacteroidetes or Bifidobacterium could not be detected in any of the treatments. Already at the higher taxonomic rank level, the three databases used (Silva, RDP and Greengenes) did not give the same results in terms of relative numbers. Since it is difficult to compare these databases and to comprehend the reasons for these differences, as described previously, a manually biocurated database dedicated to the three Phyla detected (Actinobacteria, Proteobacteria and Firmicutes) and corresponding to the V3-V4 region used in this study was created. The quantities given by our database (text in red, Figure 5) were compared to the average provided by the three public databases. Values for Actinobacteria were consistent whereas, for the Firmicutes and Proteobacteria, significant differences were observed, especially for the samples treated with bacitracin. However, no major influence in determining the phylum was observed.

\subsubsection{Genus Comparison}

As at phylum level, comparison of the different databases showed consistency for Actinobacteria whereas differences, ranging from simple to double, were observed as example for the beta-Proteobacteria and Enterococcus (text in red, Figure 6). These results do not influence the analysis because phyla have identical profiles. The comparison of genera is based on our database. For the three conditions tested, Firmicutes were largely dominated by Lactobacillus. However, two opposing tendencies were detected compared to control: 1) enrichment for the copper-exchanged zeolite diet and 2) depletion for the bacitracin group with a relative increase in favor of Enterococcus. Streptococcus and Clostridiales were found depleted in both food additives sets, virtually undetectable for the copper-exchanged zeolite treatment (Figure 6, Table 1). The Proteoacteria are mostly represented by the gamma subdivision, primarily Shigella and Escherichia and especially for chicken treated with the bacitracin (Table 1). The copper-exchanged zeolite group seems to be the only one to contain 
Table 1. Bacterial genus reads distribution for small intestine, by treatment group using our manually biocurated database.

\begin{tabular}{|c|c|c|c|c|c|c|c|}
\hline \multirow{2}{*}{$\begin{array}{c}\text { Genus } \\
\text { Lactobacillus }\end{array}$} & \multicolumn{2}{|c|}{$\begin{array}{c}\text { Number of sequences } \\
\text { Bacitracin (\%) }\end{array}$} & \multicolumn{2}{|c|}{$\begin{array}{l}\text { Number of sequences } \\
\text { Control (\%) }\end{array}$} & \multicolumn{2}{|c|}{$\begin{array}{c}\text { Number of sequences } \\
\text { Zeolite (\%) }\end{array}$} & \multirow{2}{*}{$\begin{array}{c}\text { Phylum } \\
\text { Firmicutes }\end{array}$} \\
\hline & 88,795 & $(45.09)$ & 137,938 & $(66.91)$ & 182,205 & $(92.40)$ & \\
\hline Enterococcus & 56,333 & $(28.61)$ & 13,515 & $(6.56)$ & 1209 & $(0.61)$ & Firmicutes \\
\hline Clostridium & 13,686 & $(6.95)$ & 17,809 & $(8.63)$ & 1561 & $(0.79)$ & Firmicutes \\
\hline Shigella & 6886 & $(3.50)$ & 2700 & $(1.31)$ & 79 & $(0.04)$ & Proteobacteria \\
\hline Escherichia & 6855 & $(3.48)$ & 2720 & $(1.31)$ & 104 & $(0.05)$ & Proteobacteria \\
\hline Klebsiella & 1788 & $(0.90)$ & 419 & $(0.20)$ & 2 & $(0.00)$ & Proteobacteria \\
\hline Brevibacterium & 1029 & $(0.52)$ & 351 & $(0.17)$ & 146 & $(0.07)$ & Proteobacteria \\
\hline Enterobacter & 1027 & $(0.52)$ & 190 & $(0.09)$ & 12 & $(0.00)$ & Proteobacteria \\
\hline Staphylococcus & 875 & $(0.44)$ & 1023 & $(0.49)$ & 274 & $(0.14)$ & Proteobacteria \\
\hline Brachybacterium & 765 & $(0.39)$ & 737 & $(0.36)$ & 25 & $(0.01)$ & Proteobacteria \\
\hline Corynebacterium & 757 & $(0.38)$ & 1892 & $(0.92)$ & 271 & $(0.14)$ & Proteobacteria \\
\hline Aquabacterium & 255 & $(0.13)$ & 491 & $(0.24)$ & 144 & $(0.07)$ & Proteobacteria \\
\hline Blautia & 137 & $(0.07)$ & 110 & $(0.05)$ & 22 & $(0.01)$ & Proteobacteria \\
\hline Pseudomonas & 87 & $(0.04)$ & 210 & $(0.10)$ & 57 & $(0.03)$ & Proteobacteria \\
\hline Pantoea & 52 & $(0.03)$ & 11 & $(0.00)$ & 19 & $(0.01)$ & Actinobacteria \\
\hline Comamonas & 50 & $(0.02)$ & 104 & $(0.05)$ & 46 & $(0.02)$ & Actinobacteria \\
\hline Anaerostipes & 37 & $(0.02)$ & 29 & $(0.01)$ & 8 & $(0.00)$ & Actinobacteria \\
\hline Bacillus & 36 & $(0.02)$ & 13 & $(0.00)$ & 1310 & $(0.66)$ & Actinobacteria \\
\hline Yaniella & 33 & $(0.01)$ & 15 & $(0.00)$ & 2 & $(0.00)$ & Actinobacteria \\
\hline Micrococcus & 26 & $(0.01)$ & 2 & $(0.00)$ & 19 & $(0.01)$ & Actinobacteria \\
\hline Burkholderia & 23 & $(0.01)$ & 2 & $(0.00)$ & 34 & $(0.02)$ & Actinobacteria \\
\hline Proteus & 23 & $(0.01)$ & 62 & $(0.03)$ & 0 & $(0.00)$ & Actinobacteria \\
\hline Fusicatenibacter & 21 & $(0.01)$ & 43 & $(0.02)$ & 24 & $(0.01)$ & Bacteroidetes \\
\hline Bacteroides & 20 & $(0.01)$ & 37 & $(0.02)$ & 25 & $(0.01)$ & Bacteroidetes \\
\hline Alistipes & 19 & $(0.00)$ & 17 & $(0.00)$ & 9 & $(0.00)$ & Firmicutes \\
\hline Mitsuaria & 18 & $(0.00)$ & 14 & $(0.00)$ & 32 & $(0.02)$ & Firmicutes \\
\hline Caulobacter & 12 & $(0.00)$ & 27 & $(0.01)$ & 42 & $(0.02)$ & Firmicutes \\
\hline Arthrobacter & 12 & $(0.00)$ & 11 & $(0.00)$ & 24 & $(0.01)$ & Firmicutes \\
\hline Acinetobacter & 8 & $(0.00)$ & 22 & $(0.01)$ & 20 & $(0.01)$ & Firmicutes \\
\hline Novosphingobium & 6 & $(0.00)$ & 17 & $(0.00)$ & 59 & $(0.03)$ & Firmicutes \\
\hline Marvinbryantia & 6 & $(0.00)$ & 11 & $(0.00)$ & 10 & $(0.00)$ & Firmicutes \\
\hline Roseburia & 6 & $(0.00)$ & 4 & $(0.00)$ & 5 & $(0.00)$ & Firmicutes \\
\hline Streptococcus & 4 & $(0.00)$ & 5986 & $(2.90)$ & 393 & $(0.2)$ & Firmicutes \\
\hline Janibacter & 4 & $(0.00)$ & 6 & $(0.00)$ & 62 & $(0.03)$ & Firmicutes \\
\hline Coprococcus & 3 & $(0.00)$ & 5 & $(0.00)$ & 6 & $(0.00)$ & Firmicutes \\
\hline Brevibacillus & 2 & $(0.00)$ & 2 & $(0.00)$ & 110 & $(0.06)$ & Firmicutes \\
\hline Hespellia & 2 & $(0.00)$ & 11 & $(0.00)$ & 2 & $(0.00)$ & Firmicutes \\
\hline Lactococcus & 2 & $(0.00)$ & 255 & $(0.12)$ & 35 & $(0.02)$ & Firmicutes \\
\hline Rothia & 0 & $(0.00)$ & 14 & $(0.00)$ & 5 & $(0.00)$ & Firmicutes \\
\hline Weissella & 0 & $(0.00)$ & 164 & $(0.08)$ & 14 & $(0.00)$ & Firmicutes \\
\hline
\end{tabular}




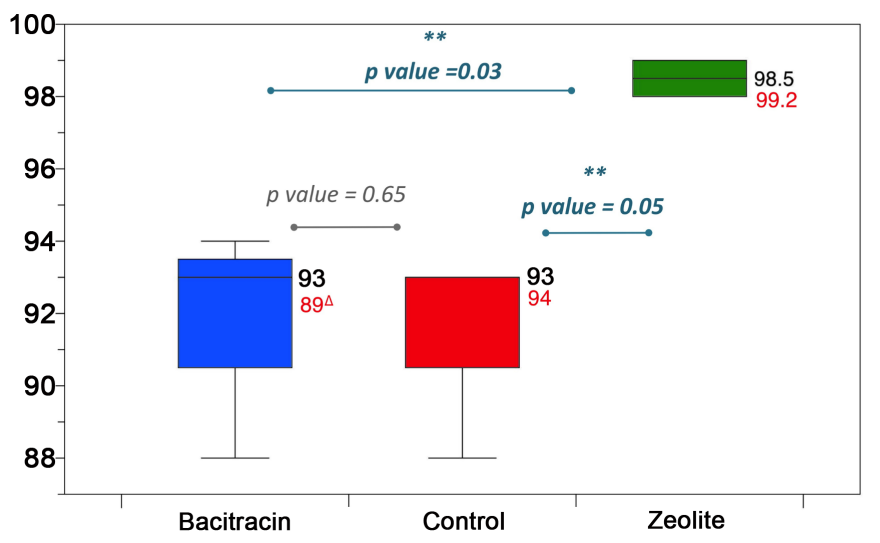

(a)

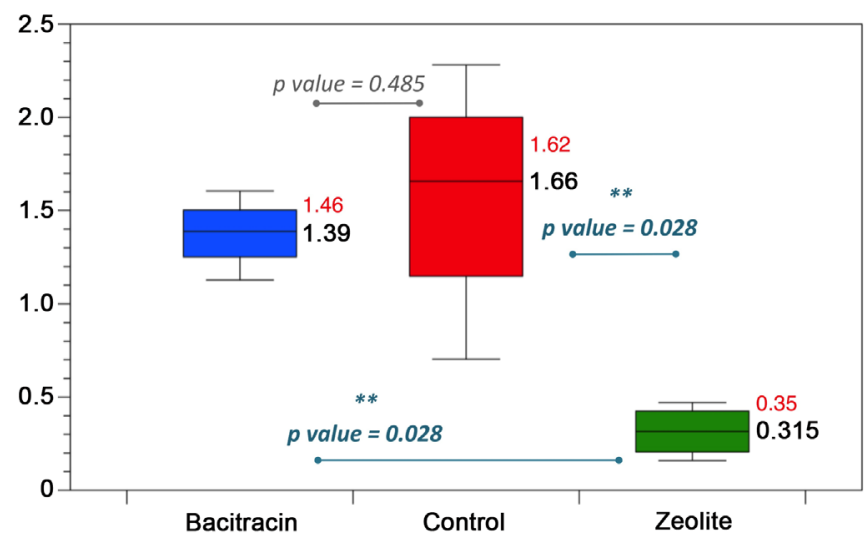

(c)

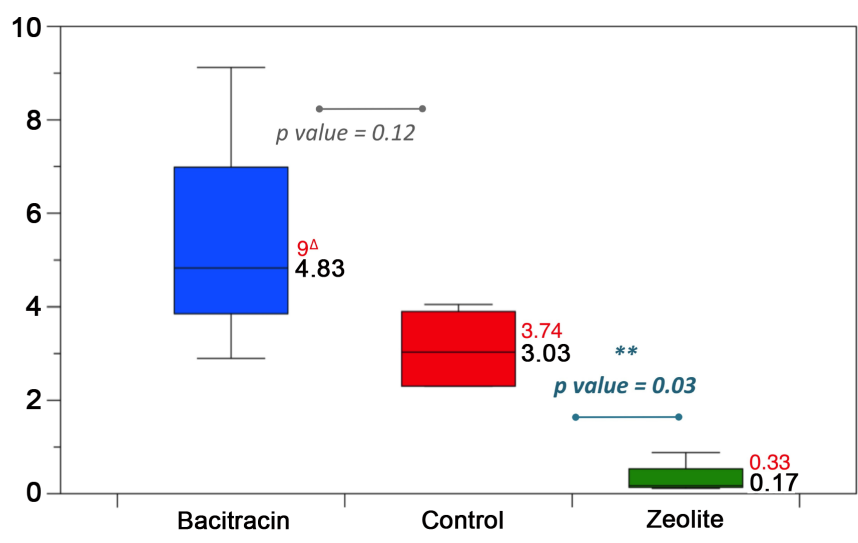

(b)

Figure 5. Comparison taxonomic assignments at phylum level using Silva, RDP and Greengenes database with VAMPS and MG-RAST online classifiers. (a), (b) and (c) show percentage of Firmicutes, Proteobacteria and Actinobacteria for each treatment (blue bacitracin, red: control and green: copper-exchanged zeolite). Numbers in black represent the mean value obtained for the three $16 \mathrm{~S}$ reference databases and the two classifiers while values in red represent the result obtained against our dedicated database. Significant differences are shown by ${ }^{*}(p<0.05)$ and $\Delta$ represents significant differences between the results obtained with the public and dedicated databases.

alpha-and beta-Proteobacteria (18\% and $8.8 \%$ ) but in a too low proportion to be considered as significant. The Actinobacteria displayed a majority of Corynebacterium with the exception of the bacitracin set that contains a majority of Brevibacterium. A significant depletion of Brachybacterium was observed in the copper-exchanged zeolite group. However, as for the Proteobacteria, the total percentage of Actinobacteria was too low in this sample (less than $0.5 \%$ ) to be interpreted (Figure 6).

\subsubsection{Species Comparisons}

For the 9 preponderant order/families/genus that summarize the three microbiota studied (Figure 7), we first checked if species could be unambiguously differentiated using the 16S rRNA V3-V4 region. Concerning the Lactobacillus, the three majority species (L. johnsonii, L. reuteri and L. gasseri) have very similar sequences but are perfectly distinguishable as shown in the tree of distance regardless the identity percentage cut-off used (Figure S5). The vast majority of assignments were completed between $100 \%$ and $98 \%$ identity. For Streptococcus, all sequences were restricted to the $S$. bovis group [45] but species are hardly or not even separable (Figure S6). We obtained similar results with the Enterococcus, all sequences belonging to the group of E. faecium, E. 


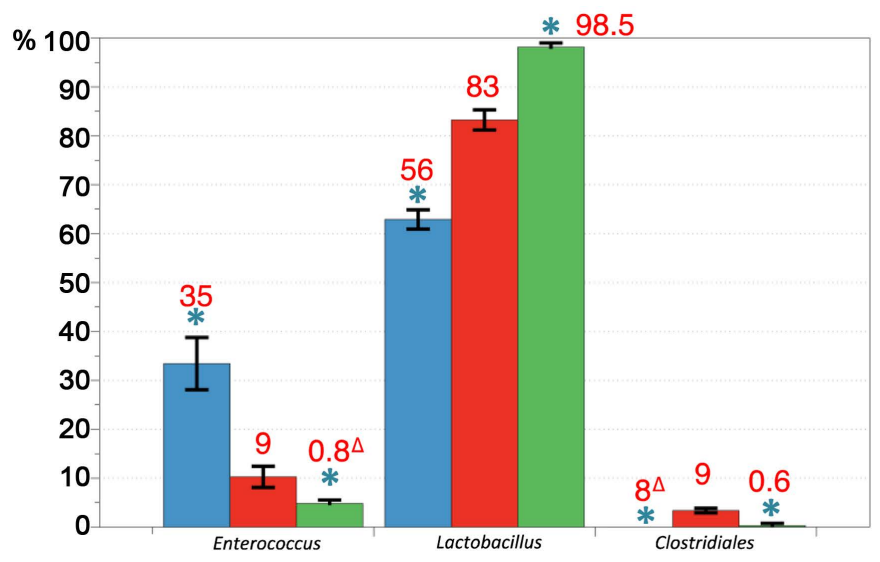

(a)

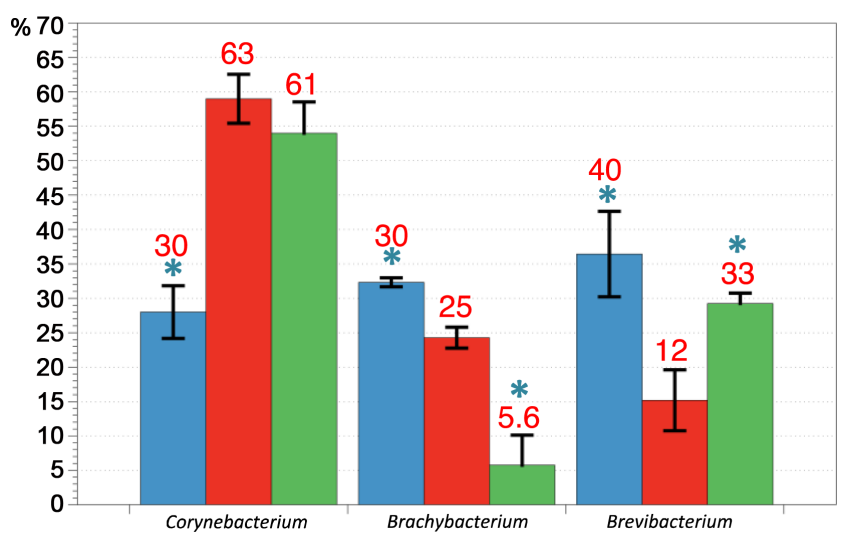

(c)

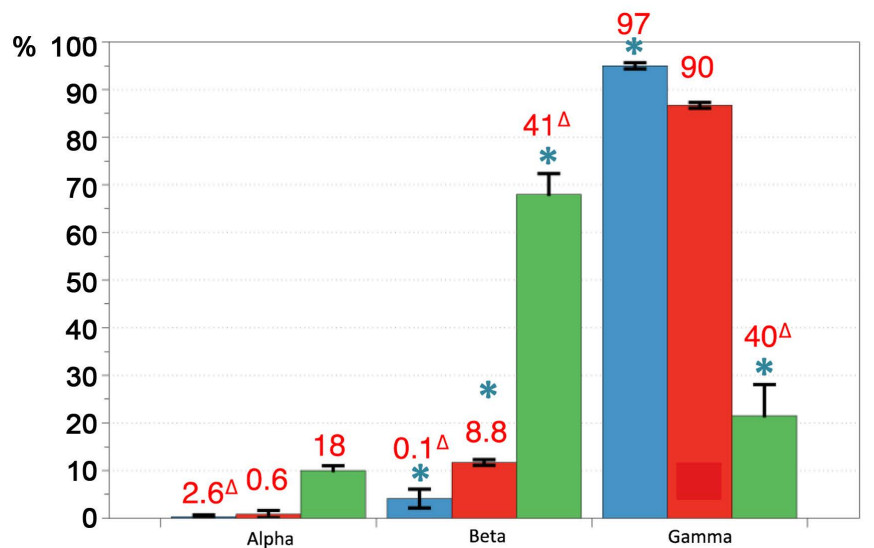

(b)

Figure 6. Comparison of order/family/genus taxonomic assignments using Silva, RDP and Greengenes database with VAMPS and MGRAST online classifiers. (a) Firmicutes major genus: Enterococcus, Lactobacillus, Clostridiales, (b) Proteobacteria major subdivisions (c) Actinobacteria genus: Corynebacterium, Brachybacterium and Brevibacterium. (Blue bacitracin, red: control and green: copperexchanged zeolite). Numbers in black represent the mean value obtained for the three $16 \mathrm{~S}$ reference databases and the two classifiers while values in red represent the result obtained against our dedicated database. Significant differences are shown by ${ }^{*}$ (between each treatment) $(p<0.05)$ and $\Delta$ (between our database and 3 others studied).

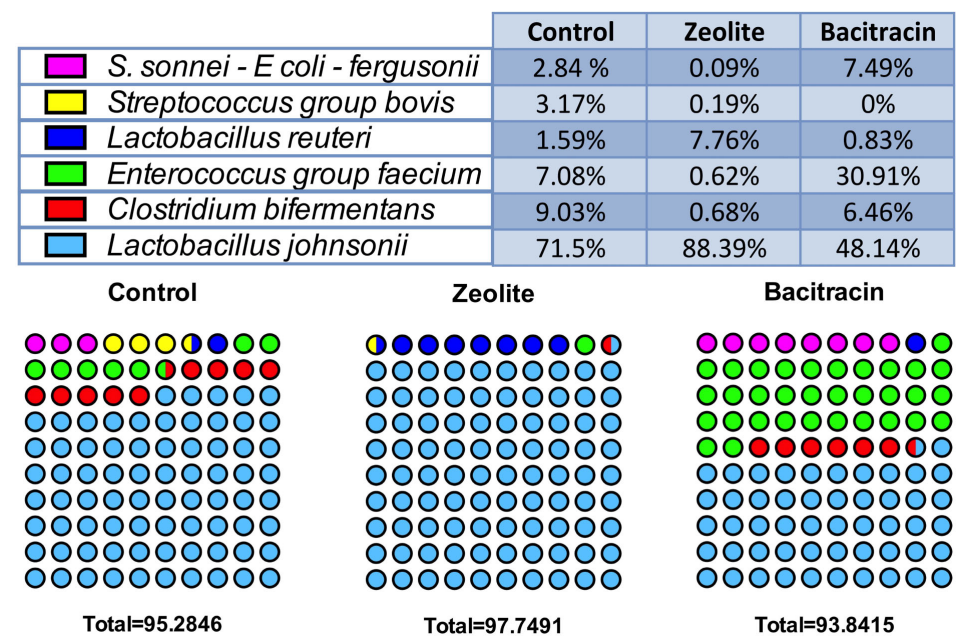

Figure 7. Contingency dots showing the distribution of the species in the small intestine microbiota of chicken for the three diets. The six most represented bacteria are colored dot-symbolized according to their proportion in each experienced-food groups. 
ratti, E. villorum, E. hirae, E. durans and E. mundtii species that cannot be differentiated using this marker (100\% identical, data not shown). This was the case also for, Escherichia and Shigella since the three identified species, E. coli, E. fergusonii and $S$. sonnei are also indistinguishable (Figure S7). Finally, for the genus Clostridium, all sequences belonged to the Peptostreptoclostridium group and separated into a major new species akin to $P$. bifermentans and a minoritory group (less than $1 \%$ ) corresponding to $P$. difficile (Figure S8). Based on this information, we compared the three groups and showed that the bacitracin treatment results in depletion in L. johnsonii and disappearance of Streptococcus group bovis in favour of an enrichment in Enterobacteria (Escherichia, Shigella), Clostridium bifermentans-like and Enterococcus of faecium group (Figure 7). While there was a shift of microbiota for this treatment, there was a complete reduction of microbial complexity for the copper-exchanged zeolite treated animals with the exclusive presence of $L$. johnsonii and L. reuteri, the latter being strongly enriched compared to other diets (Figure 7).

\section{Discussion}

Final average body weight was 10 to $20 \%$ less than the genetic potential of the bird's strain

(http://en.aviagen.com/assets/Tech Center/Ross Broiler/Ross-PM3-Broiler-PO-2014-E N.pdf). Commercial performances are often $10 \%$ lower than the genetic potential due to non-ideal environment of farms. In this study, stocking density was the highest that can be found in European field conditions, in order to create room of improvement for the tested additives and make sure that growth of treated groups will be significantly improved compared to the control. As a consequence, the level of performance of birds is in coherence with expectations. Animal's growth was not significantly different between copper-exchanged zeolite group and bacitracin group, and both groups were significantly heavier than the control group. Moreover, copper-exchanged zeolite seemed to enable a more homogeneous population than the 2 other groups. Anyway, these statements have to be taken with care since average weight and standard deviation were measured on birds, avoiding the extreme individuals. Therefore, the zootechnical conclusions may not be extrapolated to the whole population. Anyway, the study was designed to provide intestinal samples of animals that had significantly different weights, due to the addition of growth promoters in their diet, and this objective was achieved.

A correlation between small intestine total weight and chicken body weight was observed which is consistent with the studies of Yang et al. that showed that the weight of the intestine increased with body weight and Jamroz et al. that indicated that the increase in small intestine weight allows broiler chickens to reach a heavier body weight faster than control chickens [46] [47]. In our study, both fed additives increased the diameter of the jejunum, and to a lesser extent, of duodenum and ileum. The main important morphometric changes resulted in heavier and longer jejunum and ileum segments. Thus, copper-exchanged zeolite increased the small intestine surface volume ratio and consequently may increase both the absorptive area and the mucosal hydrolysis capacity [46]. It would have been interesting to measure the intestinal villi 
length to confirm this increase of absorption surface. In our study, the basic diet consisted mainly of wheat, corn and soybean that contain non-starch polysaccharides (NSPs). The increase in viscosity of intestine extract in the control chicken can be derived from a significant amount of soluble NSP in the bolus that would lead to poorer growth performance [48]. Indeed, it has been shown that higher viscosity of the intestinal contents reduce the speed of feed bolus and digestive enzymes diffusion, delay their action and subsequently, reduce the digestibility of nutrients [49] [50]). We could therefore think that the decrease of the digesta viscosity observed in supplemented animals may contribute to better nutrient retention and could subsequently explain the enhanced growth performance [51]. The reduction of intestinal contents viscosity is often associated with activity of microbial NSP-degrading enzymes such as phytases [52], xylanases [50] or beta-glucanases [51]. So, we could hypothesize that quantitative and qualitative changes observed in the microbial GIT communities of both supplemented groups of animals could be responsible for a better NSP fermentation, improving nutrient digestibility and then growth performance and decrease the intestinal viscosity as previously observed in former studies [53].

The strategy choosen in this work was to study treatment-dependent pooled samples, in order to average the impact of inter-individual microbiota variability . This strategy was essential to drive effectively this pilot experience. In the light of our first results, we will soon set up an experimental protocol allowingthe study of these individual variations. In addition, the Best-Hit assignment method was preferred to OTUs approach as more accurate as the clustering approach which gave very variable results depending on the tools used (U-search, SLP or CD-hit).

As in previous studies, we showed that main phyla present in the chicken small intestine is Firmicutes and to a lesser extent Proteobacteria. It was also shown that bacitracin and copper-exchanged zeolite supplementation differentially modulate microbiota composition [54]. But contrary to Wei et al, no Bacteroidetes were found in our samples [55].

Treatment with copper-exchanged zeolite significantly reduced the bacterial phyla diversity present in the small intestine of broilers and this depletion led to a predominance of Firmicutes (ca. 99\%) and an elimination of pathogenic genera such as Enterococcus, Shigella or Escherichia. These results suggested that copper-exchanged zeolite acts as a selector that can either inhibit the growth of pathogens or promote the growth of Lactobacillus species, supporting a healthy digestive system through "competitive exclusion" of pathogenic bacteria [56] [57], acidification of the GIT through lactic and acetic acids production [58], stimulation of the immune system [59] [60], production of antimicrobial compounds like reuterin [61], gassericin [62] or lactacin [63] and maintenance of the intestinal barrier integrity [64]. The mechanism responsible for the selection of flora remains to highlight. As Lactobacillus are predominant in crop and gizzard [65], it would be interesting to investigate if copperexchanged zeolite supplementation also enriched the upper GIT of copper-exchanged zeolite treated chicken.

In our study, we have also demonstrated that, even if both treatments tend to improve, with varying intensity, the growth performance of chickens, their impact on the 
intestinal microbiota differed totally. Some authors showed similar results [54]. Thus, unlike copper-exchanged zeolite, sub-therapeutic treatment with zinc bacitracin caused a substitution of a part of the Lactobacillus by Enteroccoccus, acting as probiotics and explaining growth improvements observed [18].

As zinc bacitracin normally targets Enterococci [66], this result suggested that the selected species of our study could be resistant to this antibiotic. However, to identify these species, we faced the fact that, if V3-V4 region of the 16s RNA is suitable to distinguish most bacterial species, it seemed insufficiently variable to identify closely related ones as previously described [67] [68]. Nevertheless, for the five species of Enterococcus recruited, E. ratti and E. villorum primarily described in pigs and rats [68] [69] and E. hirae, associated with morbid events in broilers [70] can logically be excluded in favour of $E$. faecium and $E$. durans, both commensal of poultry small intestines [71]), and having a high prevalence of bacitracin-resistance [72] [73] [74].

Escherichia was previously reported to be more prevalent in small intestine of chickens that consumed zinc bacitracin [75], which supports our observation. Indeed, the antibiotic treatment increased a community of Proteobacteria indistinctly identifiedas Shigella and/or Escherichia species.

The only clear common effect of both treatments is the elimination of Streptococcus bovis Streptococcus equinus complex (SBSEC) community. Streptococcus is a complex genus with a frequently amended classification [76]. Still, of the three possible species (or subspecies) present in the control samples and lacking in the two additives diets, $S$. infantarius remains the most probable since already described in chicken's intestine and susceptible to bacitracin [75] whereas $S$. macedonicus is mostly associated with food environment [77] and $S$. pasteurianis is mostly part of the normal flora ofhumans, also isolated from various infection sites [78]. In addition, $S$. infantarius harbors less virulence factors than other genus of the $S$. gallolyticus group, which would explain their negative effect on "control" chick's growth without pathogenic symptoms [79].

It would however be interesting to duplicate the experience with a new batch of chicks from a different hatchery to see if the orientation of the flora is repeatable or if it depends on the initial flora.

\section{Conclusion}

In conclusion, our study provides new information on the compared effects of zinc bacitracin and a copper-exchanged zeolite on broiler chickens intestinal microbiota. Tested copper-exchanged zeolite, despite differences with the antibiotic in terms of weight gain, enabled higher weights than control on birds and seems to act on chickens small intestinal morphometry and health. This additive promoted the colonization of beneficial Lactobacillus could result in a direct benefit for the chicken health and growth.

\section{Acknowledgements}

The authors thank Luis Alberto Acuña Amador, Laurence Lalanne-Cassou and Hélène Le Pocher for their technical assistance. 


\section{References}

[1] Hooper, L.V., Midtvedt, T. and Gordon, J.I. (2002) How Host-Microbial Interactions Shape the Nutrient Environment of the Mammalian Intestine. Annual Review of Nutrition, 22, 283-307. https://doi.org/10.1146/annurev.nutr.22.011602.092259

[2] Waite, D.W. and Taylor, M.W. (2015) Exploring the Avian Gut Microbiota: Current Trends and Future Directions. Frontiers in Microbiology, 6, 673. https://doi.org/10.3389/fmicb.2015.00673

[3] Jukes, T.H. and Williams, W.L. (1953) Nutritional Effects of Antibiotics. Pharmacological Reviews, 5, 381-420.

[4] Coates, M.E., Fuller, R., Harrison, G.F., Lev, M. and Suffolk, S.F. (1963) A Comparison of the Growth of Chicks in the Gustafsson Germ-Free Apparatus and in a Conventional Environment, with and without Dietary Supplements of Penicillin. British Journal of Nutrition, 17, 141-150. https://doi.org/10.1079/BJN19630015

[5] Gaskins, H.R., Collier, C.T. and Anderson, D.B. (2002) Antibiotics as Growth Promotants: Mode of Action. Animal Biotechnology, 13, 29-42.

https://doi.org/10.1081/ABIO-120005768

[6] Niewold, T.A. (2007) The Nonantibiotic Anti-Inflammatory Effect of Antimicrobial Growth Promoters, the Real Mode of Action? A Hypothesis. Poultry Science, 86, 605-609. https://doi.org/10.1093/ps/86.4.605

[7] Samanidou, V.F. and Evaggelopoulou, E.N. (2008) Chromatographic Analysis of Banned Antibacterial Growth Promoters in Animal Feed. Journal of Separation Science, 31, 20912112. https://doi.org/10.1002/jssc.200800075

[8] Mai, V. and Morris, J.G.J. (2004) Colonic Bacterial Flora: Changing Understandings in the Molecular Age. Journal of Nutrition, 134, 459-464.

[9] Stokstad, E.L., Jukes, T.H., et al. (1949) The Multiple Nature of the Animal Protein Factor. The Journal of Biological Chemistry, 180, 647-654.

[10] Libby, D.A. and Schaible, P.J. (1955) Observations on Growth Responses to Antibiotics and Arsonic Acids in Poultry Feeds. Science, 121, 733-734.

[11] Gustafson, R.H. and Bowen, R.E. (1997) Antibiotic Use in Animal Agriculture. Journal of Applied Microbiology, 83, 531-541. https://doi.org/10.1046/j.1365-2672.1997.00280.x

[12] Johnston, A.M. (2001) Animals and Antibiotics. International Journal of Antimicrobial Agents, 18, 291-294. https://doi.org/10.1016/S0924-8579(01)00379-X

[13] Barton, M.D. (2000) Antibiotic Use in Animal Feed and Its Impact on Human Healt. Nutrition Research Reviews, 13, 279-299. https://doi.org/10.1079/095442200108729106

[14] Hinton, M., Kaukas, A., Lim, S.K. and Linton, A.H. (1986) Preliminary Observations on the Influence of Antibiotics on the Ecology of Escherichia Coli and the Enterococci in the Faecal Flora of Healthy Young Chickens. Journal of Antimicrobial Chemotherapy, 18, 165-173.

[15] Hinton, M., Kaukas, A. and Linton, A.H. (1986) The Ecology of Drug Resistance in Enteric Bacteria. Society for Applied Bacteriology Symposium Series, 15, 77S-92S.

[16] Diarra, M.S. and Malouin, F. (2014) Antibiotics in Canadian Poultry Productions and Anticipated Alternatives. Frontiers in Microbiology, 5, 282. https://doi.org/10.3389/fmicb.2014.00282

[17] Smith, J.M. (2014) A Review of Avian Probiotics. Journal of Avian Medicine and Surgery, 28, 87-94. https://doi.org/10.1647/2012-031

[18] Patterson, J.A. and Burkholder, K.M. (2003) Application of Prebiotics and Probiotics in Poultry Production. Poultry Science, 82, 627-631. https://doi.org/10.1093/ps/82.4.627

[19] Ricke, S.C. (2015) Potential of Fructooligosaccharide Prebiotics in Alternative and Non- 
conventional Poultry Production Systems. Poultry Science, 94, 1411-1418. https://doi.org/10.3382/ps/pev049

[20] Michalak, I., Chojnacka, K., Dobrzanski, Z., Gorecki, H., Zielinska, A., Korczynski, M. and Opalinski, S. (2011) Effect of Macroalgae Enriched with Microelements on Egg Quality Parameters and Mineral Content of Eggs, Eggshell, Blood, Feathers and Droppings. Journal of Animal Physiology and Animal Nutrition, 95, 374-387. https://doi.org/10.1111/j.1439-0396.2010.01065.x

[21] Gheisari, A.A., Sanei, A., Samie, A., Gheisari, M.M. and Toghyani, M. (2011) Effect of Diets Supplemented with Different Levels of Manganese, Zinc, and Copper from Their Organic or Inorganic Sources on Egg Production and Quality Characteristics in Laying Hens. Biological Trace Element Research, 142, 557-571. https://doi.org/10.1007/s12011-010-8779-x

[22] Sornlake, W., Matetaviparee, P., Rattanaphan, N., Tanapongpipat, S. and Eurwilaichitr, L. (2013) Beta-Mannanase Production by Aspergillus niger BCC4525 and Its Efficacy on Broiler Performance. Journal of the Science of Food and Agriculture, 93, 3345-3351. https://doi.org/10.1002/jsfa.6183

[23] Amerah, A.M., Mathis, G. and Hofacre, C.L. (2012) Effect of Xylanase and a Blend of Essential Oils on Performance and Salmonella Colonization of Broiler Chickens Challenged with Salmonella Heidelberg. Poultry Science, 91, 943-947.

https://doi.org/10.3382/ps.2011-01922

[24] Pirgozliev, V., Bravo, D., Mirza, M.W. and Rose, S.P. (2015) Growth Performance and Endogenous Losses of Broilers Fed Wheat-Based Diets with and without Essential Oils and Xylanase Supplementation. Poultry Science, 94, 1227-1232. https://doi.org/10.3382/ps/peu017

[25] Bozkurt, M., Giannenas, I., Kucukyilmaz, K., Christaki, E. and Florou-Paneri, P. (2013) An Update on Approaches to Controlling Coccidia in Poultry Using Botanical Extracts. British Poultry Science, 54, 713-727. https://doi.org/10.1080/00071668.2013.849795

[26] Wallace, R.J., Oleszek, W., Franz, C., Hahn, I., Baser, K.H., Mathe, A. and Teichmann, K. (2010) Dietary Plant Bioactives for Poultry Health and Productivity. British Poultry Science, 51, 461-487. https://doi.org/10.1080/00071668.2010.506908

[27] Almeida, J.A., Ponnuraj, N.P., Lee, J.J., Utterback, P., Gaskins, H.R., Dilger, R.N. and Pettigrew, J.E. (2014) Effects of Dietary Clays on Performance and Intestinal Mucus Barrier of Broiler Chicks Challenged with Salmonella enterica Serovar Typhimurium and on Goblet Cell Function in Vitro. Poultry Science, 93, 839-847. https://doi.org/10.3382/ps.2013-03587

[28] Magnoli, A.P., Texeira, M., Rosa, C.A., Miazzo, R.D., Cavaglieri, L.R., Magnoli, C.E., Dalcero, A.M. and Chiacchiera, S.M. (2011) Sodium Bentonite and Monensin under Chronic Aflatoxicosis in Broiler Chickens. Poultry Science, 90, 352-357. https://doi.org/10.3382/ps.2010-00834

[29] Cabanero, A.I., Madrid, Y. and Camara, C. (2005) Effect of Animal Feed Enriched with Se and Clays on $\mathrm{Hg}$ Bioaccumulation in Chickens: In Vivo Experimental Study. Journal of Agricultural and Food Chemistry, 53, 2125-2132. https://doi.org/10.1021/jf048267v

[30] Xia, M.S., Hu, C.H. and Xu, Z.R. (2004) Effects of Copper-Bearing Montmorillonite on Growth Performance, Digestive Enzyme Activities, and Intestinal Microflora and Morphology of Male Broilers. Poultry Science, 83, 1868-1875. https://doi.org/10.1093/ps/83.11.1868

[31] Tang, Z.G., Wen, C., Wang, L.C., Wang, T. and Zhou, Y.M. (2014) Effects of Zinc-Bearing Clinoptilolite on Growth Performance, Cecal Microflora and Intestinal Mucosal Function of Broiler Chickens. Animal Feed Science and Technology, 189, 98-106. https://doi.org/10.1016/j.anifeedsci.2013.12.014 
[32] Song, J., Li, Y.L. and Hu, C.H. (2013) Effects of Copper-Exchanged Montmorillonite, as Alternative to Antibiotic, on Diarrhea, Intestinal Permeability and Proinflammatory Cytokine of Weanling Pigs. Applied Clay Science, 77-78, 52-55. https://doi.org/10.1016/j.clay.2013.01.016

[33] Hasselbacher, P. (1976) Measuring Synovial Fluid Viscosity with a White Blood Cell Diluting Pipette. A Simple, Rapid, and Reproducible Method. Arthritis \& Rheumatology, 19, 1358-1362. https://doi.org/10.1002/art.1780190620

[34] Huse, S.M., Mark Welch, D.B., Voorhis, A., Shipunova, A., Morrison, H.G., Eren, A.M. and Sogin, M.L. (2014) VAMPS: A Website for Visualization and Analysis of Microbial Population Structures. BMC Bioinformatics, 15, 41. https://doi.org/10.1186/1471-2105-15-41

[35] Meyer, F., Paarmann, D., D’Souza, M., Olson, R., Glass, E.M., Kubal, M., Paczian, T., Rodriguez, A., Stevens, R., Wilke, A., Wilkening, J. and Edwards, R.A. (2008) The Metagenomics RAST Server-A Public Resource for the Automatic Phylogenetic and Functional Analysis of Metagenomes. BMC Bioinformatics, 9, 386.

https://doi.org/10.1186/1471-2105-9-386

[36] Chao, A.L.S. (1992) Estimating the Number of Classes via Sample Coverage. Journal of the American Statistical Association, 87, 210-217. https://doi.org/10.1080/01621459.1992.10475194

[37] Chao, A. (1984) Non-Parametric Estimation of the Number of Classes in a Population. Scandinavian Journal of Statistics, 11, 265-270.

[38] Simpson, E.H. (1949) Measurement of Diversity. Nature, 163, 688. https://doi.org/10.1038/163688a0

[39] Shannon, C.E. (1948) A Mathematical Theory of Communication. The Bell System Technical Journal, 27, 379-423, 623-656.

[40] Lozupone, C.A., Hamady, M., Kelley, S.T. and Knight, R. (2007) Quantitative and Qualitative Beta Diversity Measures Lead to Different Insights into Factors That Structure Microbial Communities. Applied and Environmental Microbiology, 73, 1576-1585. https://doi.org/10.1128/AEM.01996-06

[41] Vazquez-Baeza, Y., Pirrung, M., Gonzalez, A. and Knight, R. (2013) EMPeror: A Tool for Visualizing High-Throughput Microbial Community Data. Gigascience, 2, 16.

[42] Quast, C., Pruesse, E., Yilmaz, P., Gerken, J., Schweer, T., Yarza, P., Peplies, J. and Glockner, F.O. (2013) The SILVA Ribosomal RNA Gene Database Project: Improved Data Processing and Web-Based Tools. Nucleic Acids Research, 41, D590-D596. https://doi.org/10.1093/nar/gks1219

[43] Cole, J.R., Chai, B., Farris, R.J., Wang, Q., Kulam-Syed-Mohideen, A.S., McGarrell, D.M., Bandela, A.M., Cardenas, E., Garrity, G.M. and Tiedje, J.M. (2007) The Ribosomal Database Project (RDP-II): Introducing myRDP Space and Quality Controlled Public Data. Nucleic Acids Research, 35, D169-D172. https://doi.org/10.1093/nar/gkl889

[44] DeSantis, T.Z., Hugenholtz, P., Larsen, N., Rojas, M., Brodie, E.L., Keller, K., Huber, T., Dalevi, D., Hu, P. and Andersen, G.L. (2006) Greengenes, a Chimera-Checked 16S rRNA Gene Database and Workbench Compatible with ARB. Applied and Environmental Microbiology, 72, 5069-5072. https://doi.org/10.1128/AEM.03006-05

[45] Gao, X.Y., Zhi, X.Y., Li, H.W., Klenk, H.P. and Li, W.J. (2014) Comparative Genomics of the Bacterial Genus Streptococcus Illuminates Evolutionary Implications of Species Groups. PLoS ONE, 9, e101229. https://doi.org/10.1371/journal.pone.0101229

[46] Yang, H.M., Wang W., Wang, Z.Y., Wang, J., Cao, Y.J. and Chen, Y.H. (2013) Comparative Study of Intestine Length, Weight and Digestibility on Different Body Weight Chickens. African Journal of Biotechnology, 12, 5097-5100. https://doi.org/10.5897/AJB11.4014 
[47] Jamroz, D. (2005) Comparative Characteristic of Gastrointestinal Tract Development and Digestibility of Nutrients in Young Chickens, Ducks and Geese. Proceedings of the 15th European Symposium on Poultry Nutrition, Balatonfüred, 25-29 September 2005, 74-85.

[48] Bedford, M.R. and Schulze, H. (1998) Exogenous Enzymes for Pigs and Poultry. Nutrition Research Reviews, 11, 91-114. https://doi.org/10.1079/NRR19980007

[49] Choct, M. and Annison, G. (1992) Anti-Nutritive Effect of Wheat Pentosans in Broiler Chickens: Roles of Viscosity and Gut Microflora. British Poultry Science, 33, 821-834. https://doi.org/10.1080/00071669208417524

[50] Choct, M., Hughes, R.J. and Bedford, M.R. (1999) Effects of a Xylanase on Individual Bird Variation, Starch Digestion throughout the Intestine, and Ileal and Caecal Volatile Fatty Acid Production in Chickens Fed Wheat. British Poultry Science, 40, 419-422. https://doi.org/10.1080/00071669987548

[51] Wang, Z.R., Qiao, S.Y., Lu, W.Q. and Li, D.F. (2005) Effects of Enzyme Supplementation on Performance, Nutrient Digestibility, Gastrointestinal Morphology, and Volatile Fatty Acid Profiles in the Hindgut of Broilers Fed Wheat-Based Diets. Poultry Science, 84, 875-881. https://doi.org/10.1093/ps/84.6.875

[52] Ravindran, V., Selle, P.H. and Bryden, W.L. (1999) Effects of Phytase Supplementation, Individually and in Combination, with Glycanase, on the Nutritive Value of Wheat and Barley. Poultry Science, 78, 1588-1595. https://doi.org/10.1093/ps/78.11.1588

[53] Petersen, S.T., Wiseman, J. and Bedford, M.R. (1999) Effects of Age and Diet on the Viscosity of Intestinal Contents in Broiler Chicks. British Poultry Science, 40, 364-370. https://doi.org/10.1080/00071669987467

[54] Pourabedin, M., Guan, L. and Zhao, X. (2015) Xylo-Oligosaccharides and Virginiamycin Differentially Modulate Gut Microbial Composition in Chickens. Microbiome, 3, 15.

[55] Wei, S., Morrison, M. and Yu, Z. (2013) Bacterial Census of Poultry Intestinal Microbiome. Poultry Science, 92, 671-683. https://doi.org/10.3382/ps.2012-02822

[56] Nishiyama, K., Nakazato, A., Ueno, S., Seto, Y., Kakuda, T., Takai, S., Yamamoto, Y. and Mukai, T. (2015) Cell Surface-Associated Aggregation-Promoting Factor from Lactobacillus gasseri SBT2055 Facilitates Host Colonization and Competitive Exclusion of Campylobacter jejuni. Molecular Microbiology, 98, 712-726. https://doi.org/10.1111/mmi.13153

[57] Garriga, M., Pascual, M., Monfort, J.M. and Hugas, M. (1998) Selection of Lactobacilli for Chicken Probiotic Adjuncts. Journal of Applied Microbiology, 84, 125-132. https://doi.org/10.1046/j.1365-2672.1997.00329.x

[58] Ehrmann, M.A., Kurzak, P., Bauer, J. and Vogel, R.F. (2002) Characterization of Lactobacilli towards Their Use as Probiotic Adjuncts in Poultry. Journal of Applied Microbiology, 92, 966-975. https://doi.org/10.1046/j.1365-2672.2002.01608.x

[59] Brisbin, J.T., Davidge, L., Roshdieh, A. and Sharif, S. (2015) Characterization of the Effects of Three Lactobacillus Species on the Function of Chicken Macrophages. Research in Veterinary Science, 100, 39-44. https://doi.org/10.1016/j.rvsc.2015.03.003

[60] Brisbin, J.T., Gong, J., Orouji, S., Esufali, J., Mallick, A.I., Parvizi, P., Shewen, P.E. and Sharif, S. (2011) Oral Treatment of Chickens with Lactobacilli Influences Elicitation of Immune Responses. Clinical and Vaccine Immunology, 18, 1447-1455. https://doi.org/10.1128/CVI.05100-11

[61] Montiel, R., Martin-Cabrejas, I., Langa, S., El Aouad, N., Arques, J.L., Reyes, F. and Medina, M. (2014) Antimicrobial Activity of Reuterin Produced by Lactobacillus reuteri on Listeria monocytogenes in Cold-Smoked Salmon. Food Microbiology, 44, 1-5. https://doi.org/10.1016/j.fm.2014.05.006

[62] Pandey, N., Malik, R.K., Kaushik, J.K. and Singroha, G. (2013) Gassericin A: A Circular Bacteriocin Produced by Lactic Acid Bacteria Lactobacillus gasseri. World Journal of Mi- 
crobiology and Biotechnology, 29, 1977-1987. https://doi.org/10.1007/s11274-013-1368-3

[63] Abee, T., Klaenhammer, T.R. and Letellier, L. (1994) Kinetic Studies of the Action of Lactacin F, a Bacteriocin Produced by Lactobacillus Johnsonii That Forms Poration Complexes in the Cytoplasmic Membrane. Applied and Environmental Microbiology, 60, 1006-1013.

[64] Karczewski, J., Troost, F.J., Konings, I., Dekker, J., Kleerebezem, M., Brummer, R.J. and Wells, J.M. (2010) Regulation of Human Epithelial Tight Junction Proteins by Lactobacillus Plantarum in Vivo and Protective Effects on the Epithelial Barrier. American Journal of Physiology_Gastrointestinal and Liver Physiology, 298, G851-G859. https://doi.org/10.1152/ajpgi.00327.2009

[65] Gong, J., Si, W., Forster, R.J., Huang, R., Yu, H., Yin, Y., Yang, C. and Han, Y. (2007) 16S rRNA Gene-Based Analysis of Mucosa-Associated Bacterial Community and Phylogeny in the Chicken Gastrointestinal Tracts: From Crops to Ceca. FEMS Microbiology Ecology, 59, 147-157. https://doi.org/10.1111/j.1574-6941.2006.00193.x

[66] Phillips, I. (1999) The Use of Bacitracin as a Growth Promoter in Animals Produces No Risk to Human Health. Journal of Antimicrobial Chemotherapy, 44, 725-728. https://doi.org/10.1093/jac/44.6.725

[67] Fox, G.E., Wisotzkey, J.D. and Jurtshuk, P.J. (1992) How Close Is Close: 16S rRNA Sequence Identity May Not Be Sufficient to Guarantee Species Identity. International Journal of Systematic Bacteriology, 42, 166-170. https://doi.org/10.1099/00207713-42-1-166

[68] Vancanneyt, M., Snauwaert, C., Cleenwerck, I., Baele, M., Descheemaeker, P., Goossens, H., Pot, B., Vandamme, P., Swings, J., Haesebrouck, F. and Devriese, L.A. (2001) Enterococcus villorum sp. nov., an Enteroadherent Bacterium Associated with Diarrhoea in Piglets. International Journal of Systematic and Evolutionary Microbiology, 51, 393-400. https://doi.org/10.1099/00207713-51-2-393

[69] Teixeira, L.M., Carvalho, M.G., Espinola, M.M., Steigerwalt, A.G., Douglas, M.P., Brenner, D.J. and Facklam, R.R. (2001) Enterococcus porcinus sp. nov. and Enterococcus ratti sp. nov., Associated with Enteric Disorders in Animals. International Journal of Systematic and Evolutionary Microbiology, 51, 1737-1743. https://doi.org/10.1099/00207713-51-5-1737

[70] Chadfield, M.S., Christensen, J.P., Juhl-Hansen, J., Christensen, H. and Bisgaard, M. (2005) Characterization of Enterococcus hirae Outbreaks in Broiler Flocks Demonstrating Increased Mortality Because of Septicemia and Endocarditis and/or Altered Production Parameters. Avian Diseases, 49, 16-23. https://doi.org/10.1637/7205-050604

[71] Devriese, L.A., Hommez, J., Wijfels, R. and Haesebrouck, F. (1991) Composition of the Enterococcal and Streptococcal Intestinal Flora of Poultry. Journal of Applied Bacteriology, 1, 46-50.

[72] Tremblay, C.L., Letellier, A., Quessy, S., Boulianne, M., Daignault, D. and Archambault, M. (2011) Multiple-Antibiotic Resistance of Enterococcus faecalis and Enterococcus faecium from Cecal Contents in Broiler Chicken and Turkey Flocks Slaughtered in Canada and Plasmid Colocalization of tetO and ermB Genes. Journal of Food Protection, 74, 1639-1648. https://doi.org/10.4315/0362-028X.JFP-10-451

[73] Manson, J.M., Smith, J.M. and Cook, G.M. (2004) Persistence of Vancomycin-Resistant Enterococci in New Zealand Broilers after Discontinuation of Avoparcin Use. Applied and Environmental Microbiology, 70, 5764-5768. https://doi.org/10.1128/AEM.70.10.5764-5768.2004

[74] Frei, A., Goldenberger, D. and Teuber, M. (2001) Antimicrobial Susceptibility of Intestinal Bacteria from Swiss Poultry Flocks before the Ban of Antimicrobial Growth Promoters. Systematic and Applied Microbiology, 24, 116-121. https://doi.org/10.1078/0723-2020-00004

[75] Gong, J., Yu, H., Liu, T., Gill, J.J., Chambers, J.R., Wheatcroft, R. and Sabour, P.M. (2008) 
Effects of Zinc Bacitracin, Bird Age and Access to Range on Bacterial Microbiota in the Ileum and Caeca of Broiler Chickens. Journal of Applied Microbiology, 104, 1372-1382. https://doi.org/10.1111/j.1365-2672.2007.03699.x

[76] Schlegel, L., Grimont, F., Ageron, E., Grimont, P.A. and Bouvet, A. (2003) Reappraisal of the Taxonomy of the Streptococcus bovis/Streptococcus equinus Complex and Related Species: Description of Streptococcus gallolyticus subsp. Gallolyticus subsp. nov., S. Gallolyticus subsp. Macedonicus subsp. nov. and S. Gallolyticus subsp. Pasteurianus subsp. nov. International Journal of Systematic and Evolutionary Microbiology, 53, 631-645. https://doi.org/10.1099/ijs.0.02361-0

[77] Papadimitriou, K., Ferreira, S., Papandreou, N.C., Mavrogonatou, E., Supply, P., Pot, B. and Tsakalidou, E. (2012) Complete Genome Sequence of the Dairy Isolate Streptococcus macedonicus ACA-DC 198. Journal of Bacteriology, 194, 1838-1839. https://doi.org/10.1128/JB.06804-11

[78] Punpanich, W., Munsrichoom, A. and Dejsirilert, S. (2012) Streptococcus gallolyticus Subspecies Pasteurianus meningitis in an Infant: A Case Report and Literature Review. Journal of the Medical Association of Thailand, 95, 1606-1612.

[79] Jans, C., Follador, R., Hochstrasser, M., Lacroix, C., Meile, L. and Stevens, M.J. (2013) Comparative Genome Analysis of Streptococcus Infantarius Subsp. Infantarius CJ18, an African Fermented Camel Milk Isolate with Adaptations to Dairy Environment. BMC Genomics, 14, 200. https://doi.org/10.1186/1471-2164-14-200 


\section{Supplementary Data}

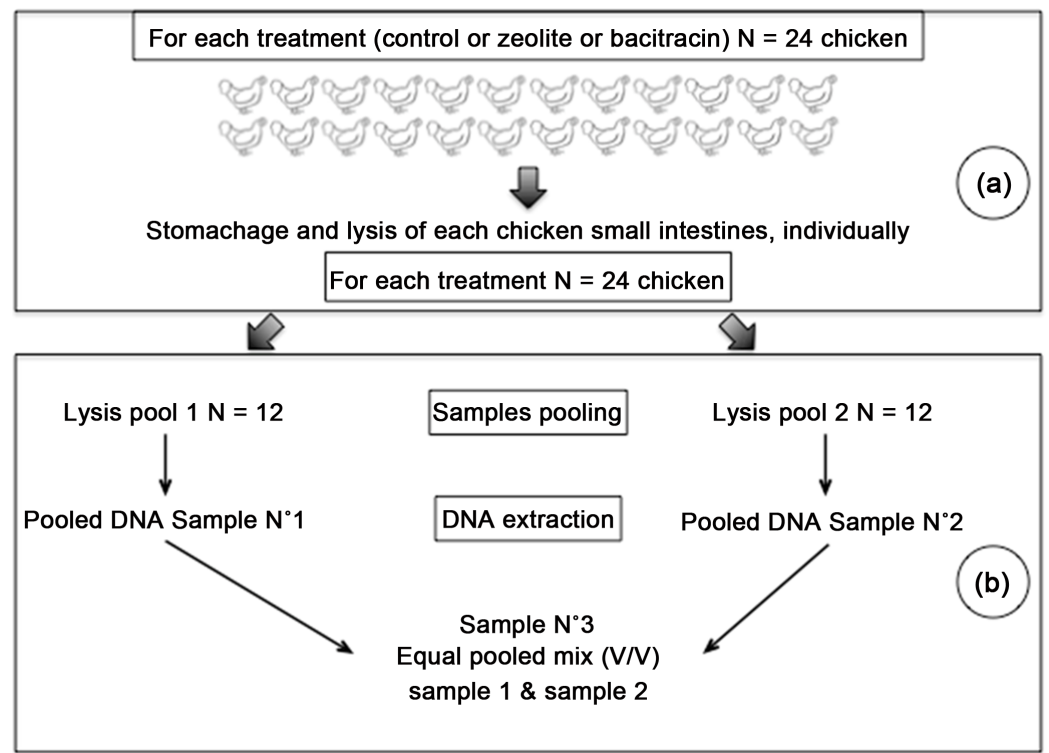

Figure S1. DNA sampling for microbiote analyses. Same protocol was used for each treatment (control, zeolite and bacitracin). Briefly, twenty four chicken small intestines were individually lysed and stomach (a). Then, two pools containing each 12 lysis products were used for DNA extraction, resulting in pooled DNA samples 1 and 2. Additionally, an equimolar mix of these two last samples was prepared, corresponding to equal pooled mix sample 3 (b).

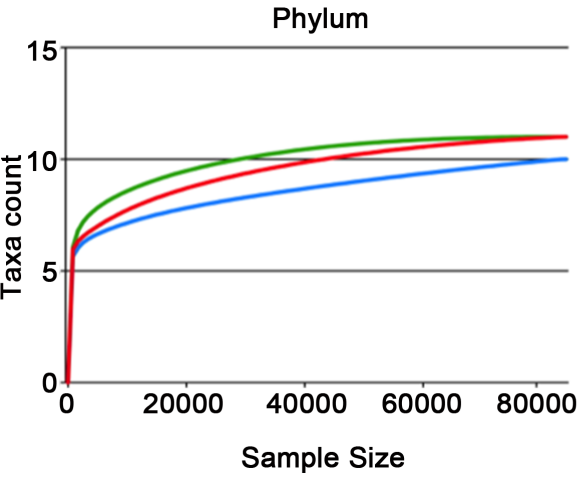

(a)

Phylum

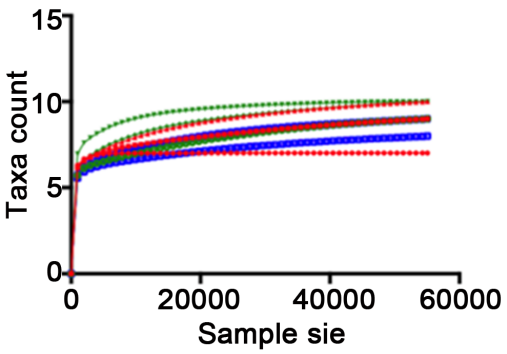

(c)

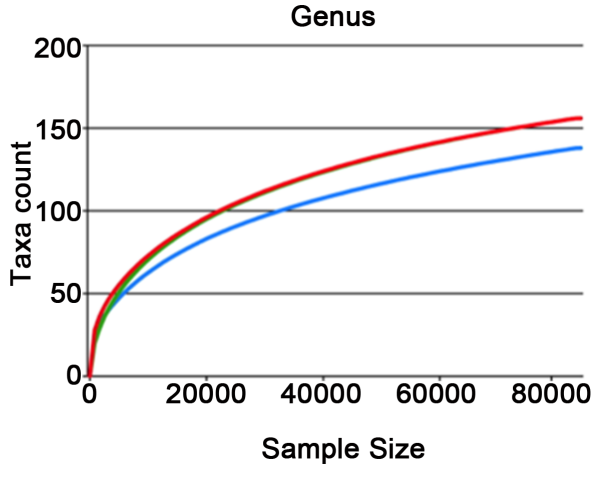

(b)

Genus

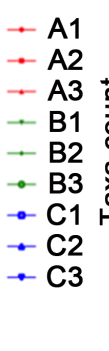

- A1
- A2
- A3
- B1
- B2
- B3
- C1
- C2
- C3

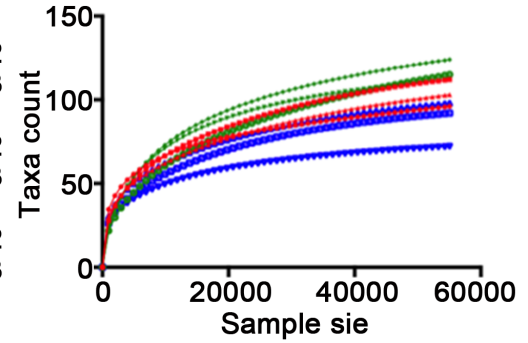

(d)

Figure S2. Rarefaction curves for the three microbiota samples. Each curve corresponds to a different sample (red: control, blue: Zn bacitracin, green: copper-exchanged zeolite). The y-axis indicates the number of species detected and the $\mathrm{x}$-axis the number of sequences analysed per sample. (a) and (b) represent pooled samples, and (c) and (d) represent all the samples. 

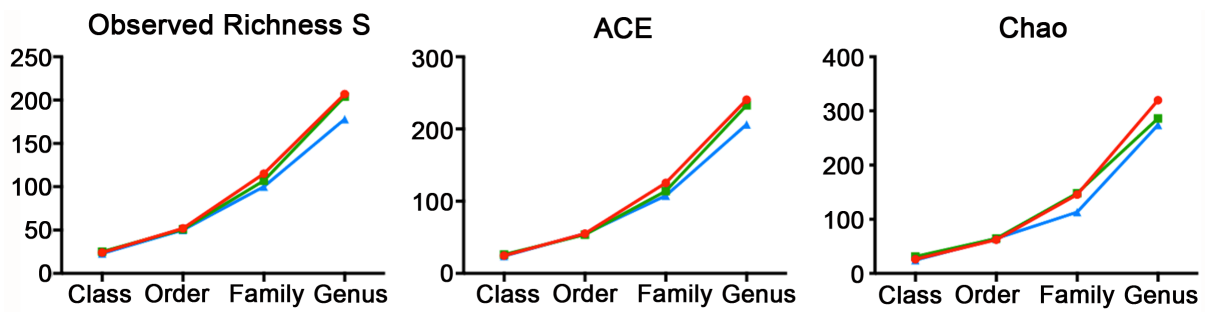

(a)
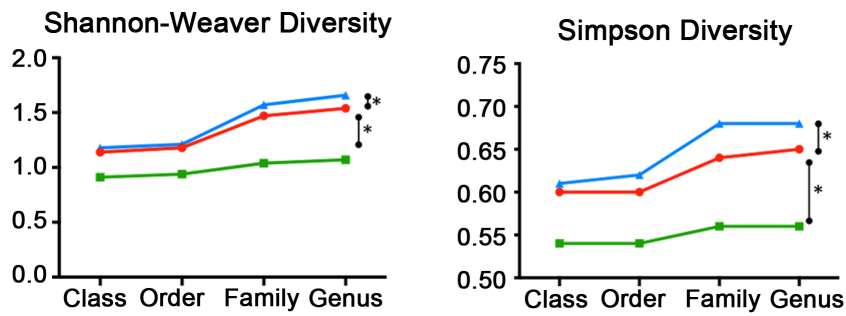

(b)

Figure S3. Microbiota richness and diversity comparisons between control and treated diets (blue: Zn-bacitracin, green: B-SAFE copper-exchanged zeolite, red: control diet). (a) Observed (S) and estimated (Chao/ACE) richness. (b) Shannon Weaver and Simpson index curves used to estimate alpha diversity (i.e., a combined assessment of the number of unique bacterial taxa and their abundance) of each sample.
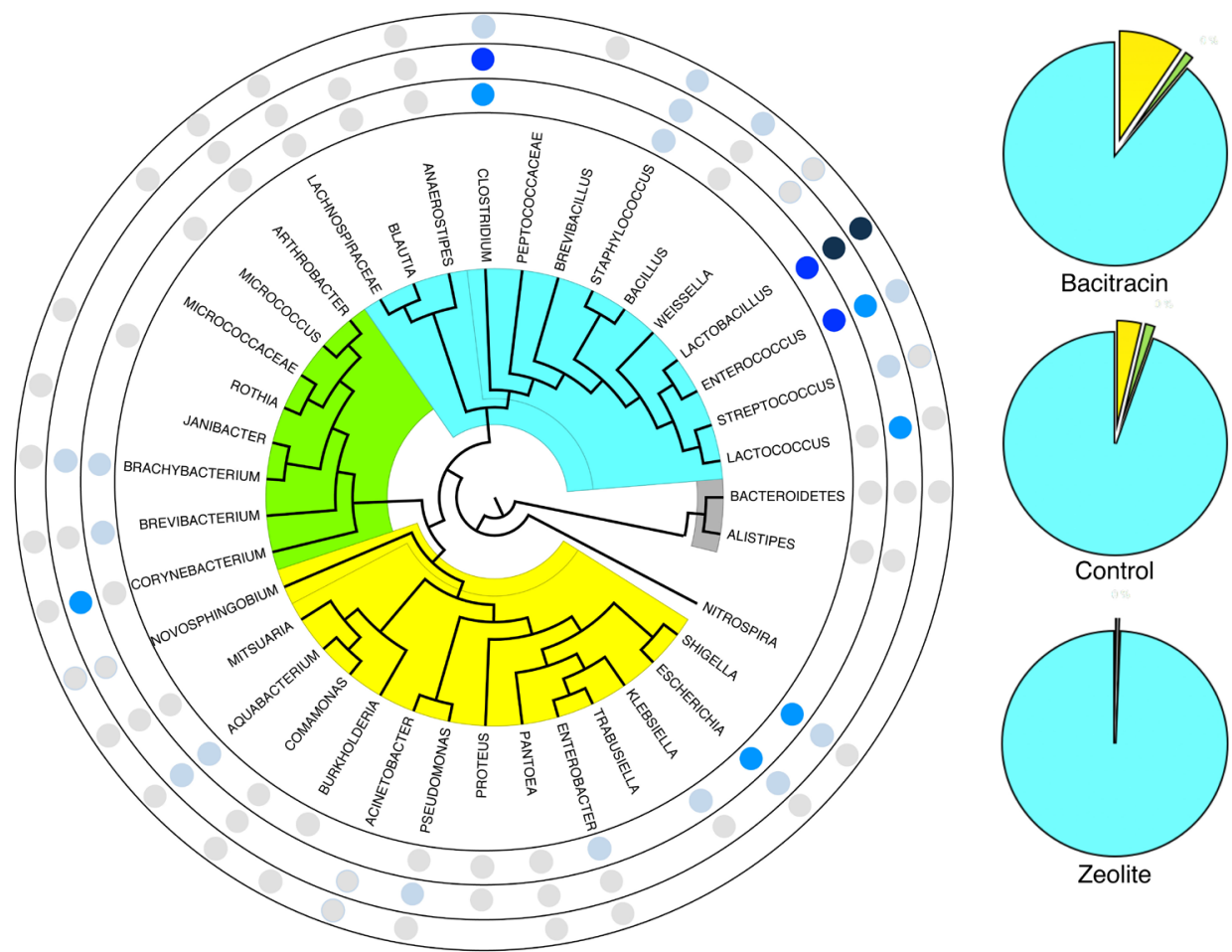

Figure S4. Left: Rotary phylogenetic representation of the predominant microbial composition of small intestine for each feed treatment (yellow: Proteobacteria, bright green: Actinobacteria, light blue: Firmicutes and grey: minority phyla Bacteroidetes and it associated genus: Alistipes). Blue points represent the rate of presence, along a gradient from the darkest (for the high percentages) to the clearer (for the low percentages). Outside circle: copper-exchanged zeolite. Middle circle: control. Inside circle: bacitracin. Right: Phylum repartition for each diet treatment (same color code as left). 


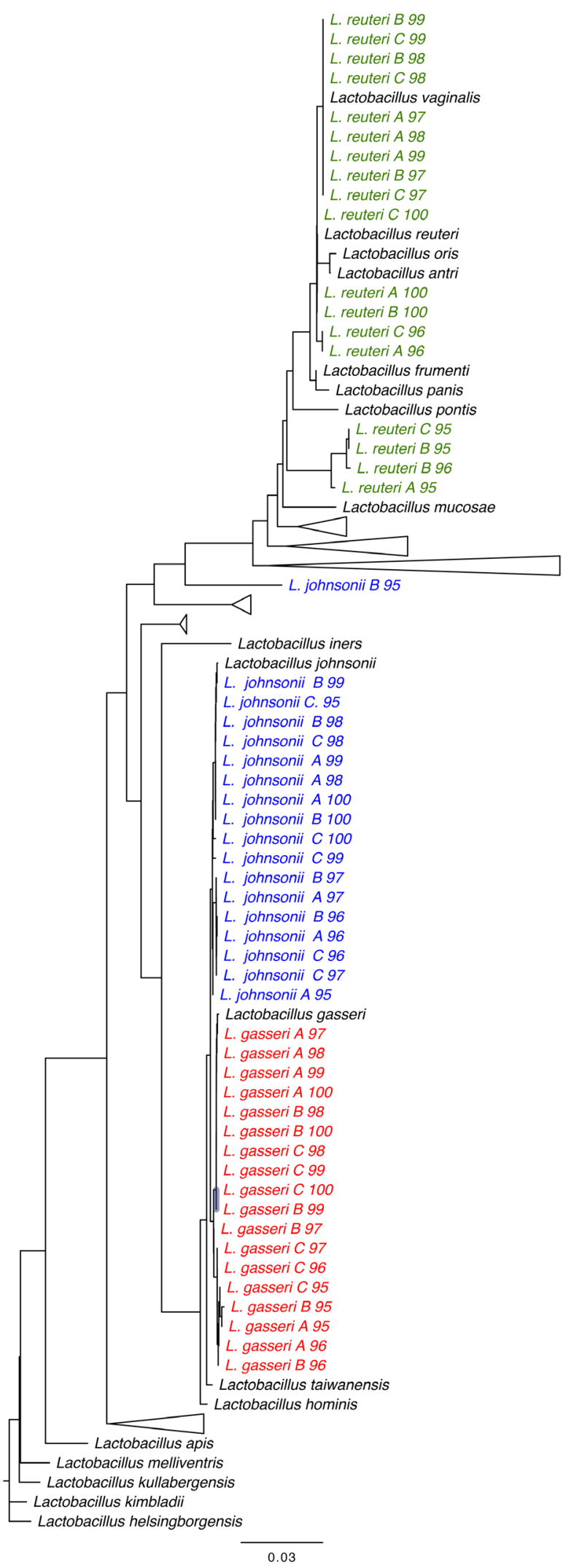

Zeolite

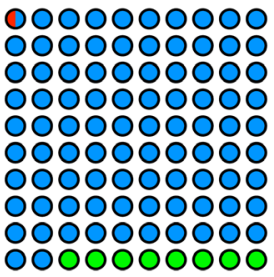

Total=181279

Control

0000000000 0000000000 0000000000 0000000000 0000000000 000000000 0000000000 0000000000 0000000 000000000

Total=137679

Bacitracin

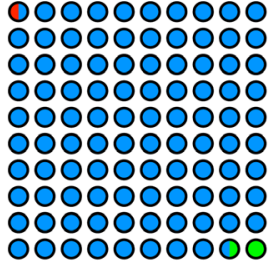

Total $=\mathbf{8 8 6 5 7}$
Lactobacillus gasser Lactobacillus johnsoni $\square$ Lactobacillus reuter
Lactobacillus gasseri cillus johnsonil Lactobacillus reuteri

Figure S5. Distance tree showing the effectiveness of the distinction of the species of Lactobacillus johnsonii, L.reuteri and L.gasseri, recruited to identity thresholds from 95 to $100 \%$. Dot representation shows the distribution of the three species in each diets. 


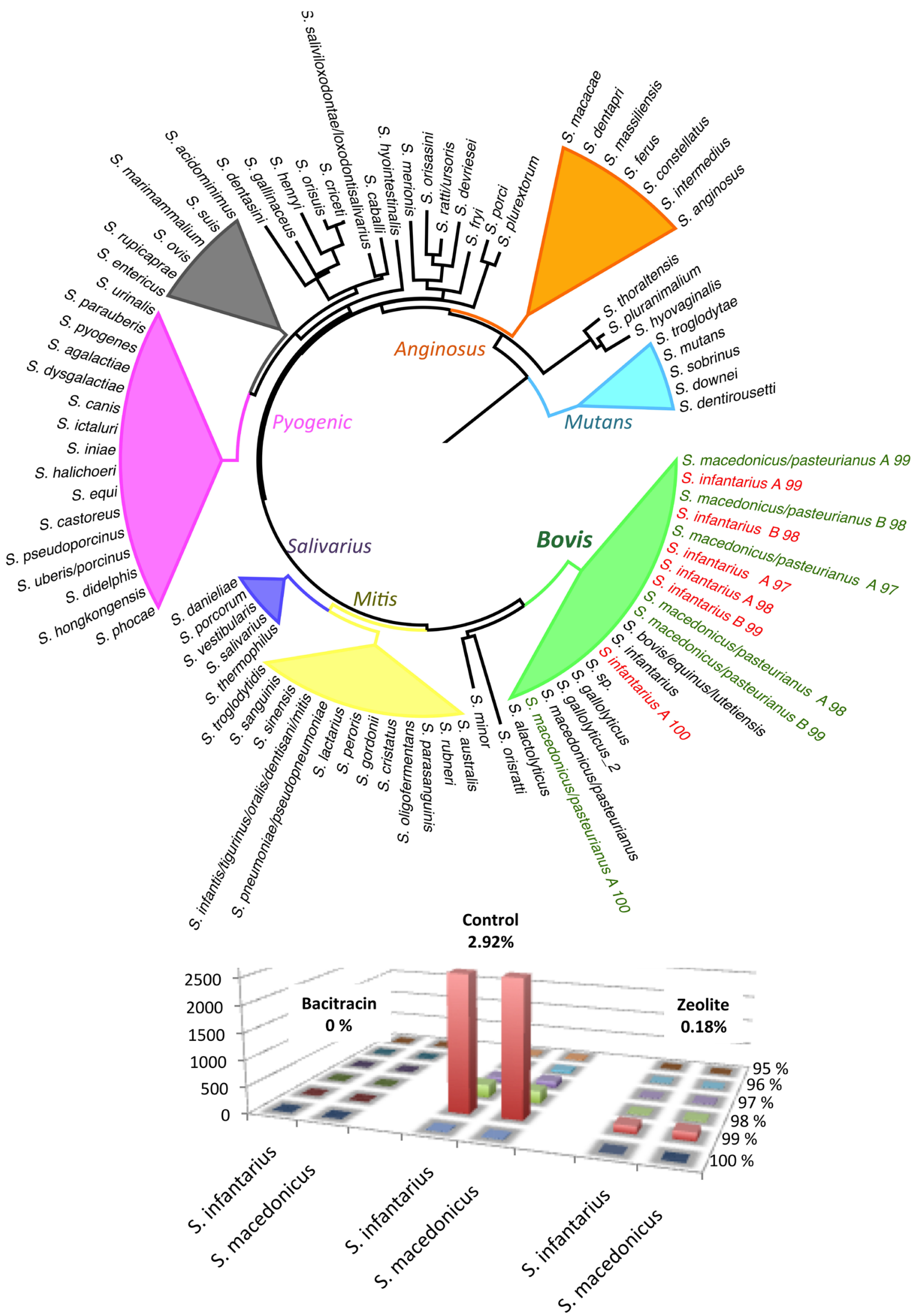

Figure S6. Distance tree showing that all Streptococcus species belong to group bovis and are mostly recruited at $99 \%$ identity threshold. 


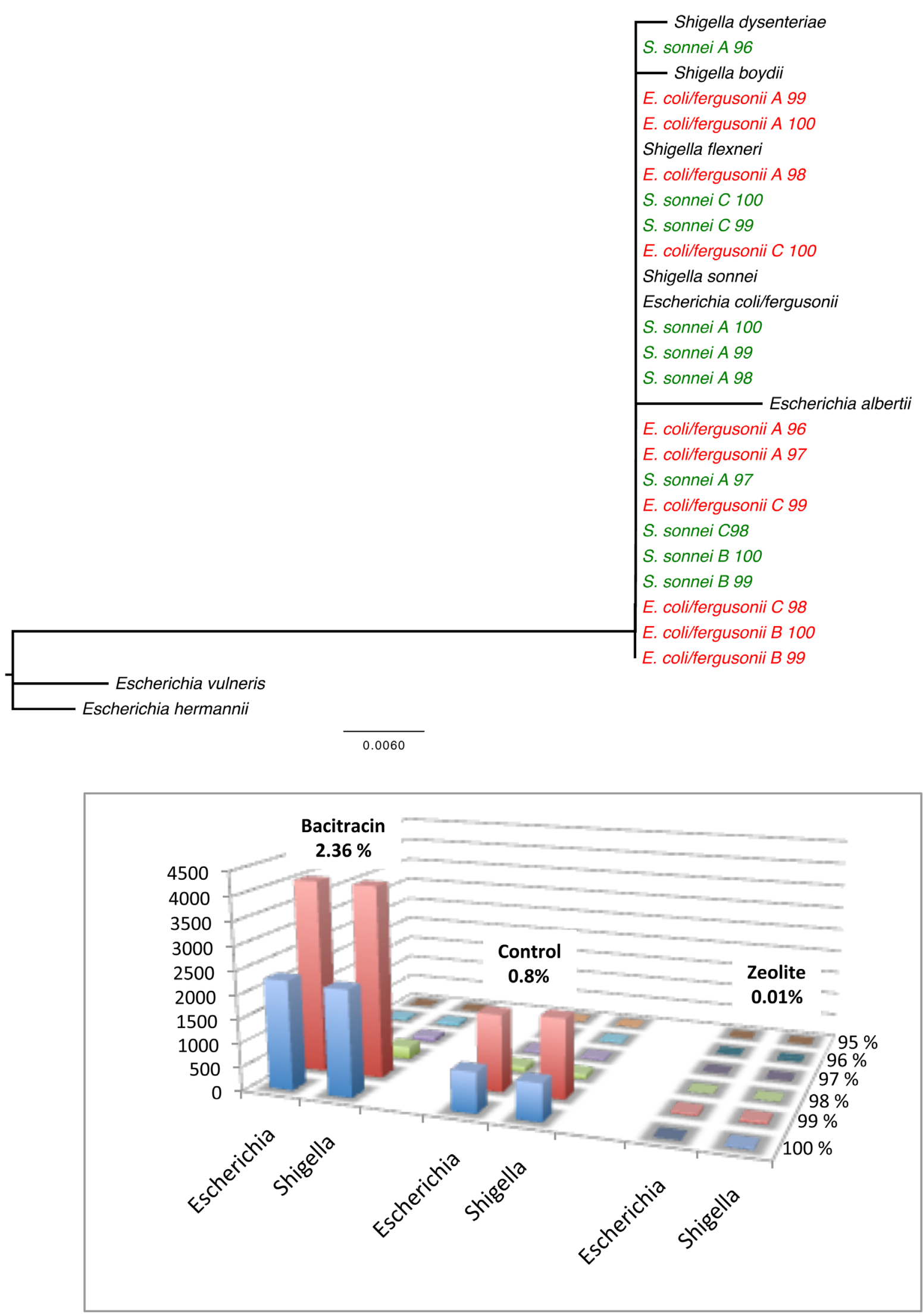

Figure S7. Distance tree showing that Shigella-Escherichia clustered together and are mostly recruited at 100\% and $99 \%$ identity threshold. 


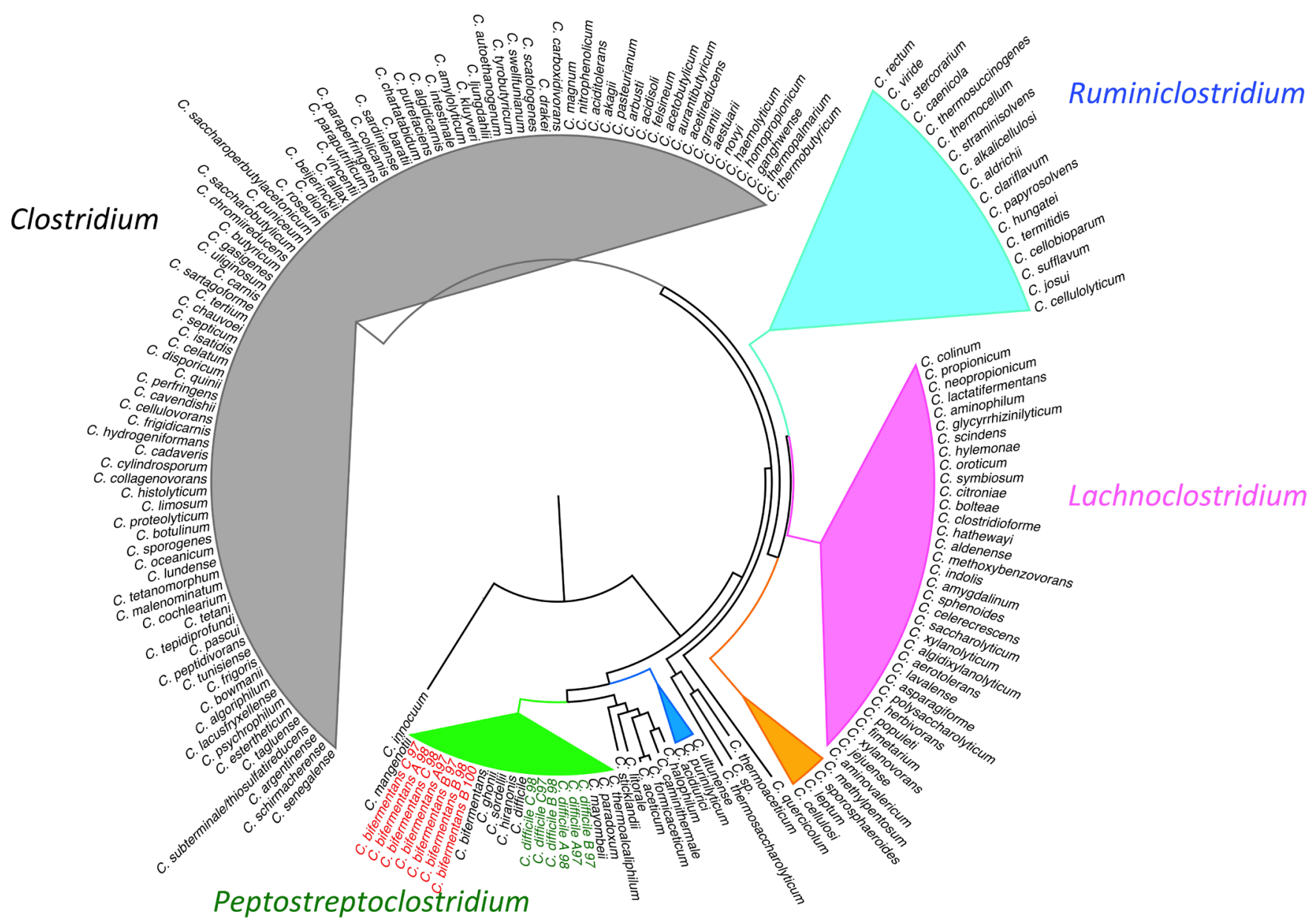

Figure S8. Distance tree showing that Clostridia genus clustered in the Peptostreptoclostridium in two groups related to $C$. bifermentans and difficile.

\section{Submit or recommend next manuscript to SCIRP and we will provide best service for you:}

Accepting pre-submission inquiries through Email, Facebook, LinkedIn, Twitter, etc.

A wide selection of journals (inclusive of 9 subjects, more than 200 journals)

Providing 24-hour high-quality service

User-friendly online submission system

Fair and swift peer-review system

Efficient typesetting and proofreading procedure

Display of the result of downloads and visits, as well as the number of cited articles

Maximum dissemination of your research work

Submit your manuscript at: http://papersubmission.scirp.org/

Or contact fns@scirp.org 